\title{
Observed Near-Storm Environment Variations across the Southern Cumberland Plateau System in Northeastern Alabama
}

\author{
ANTHONY W. LYZA \\ Department of Atmospheric and Earth Science, Severe Weather Institute-Radar and Lightning Laboratories, University of \\ Alabama in Huntsville, Huntsville, Alabama \\ TODD A. MURPHY \\ Department of Atmospheric Science, University of Louisiana at Monroe, Monroe, Louisiana \\ Barrett T. Goudeau, Preston T. Pangle, Kevin R. KnupP, and Ryan A. Wade \\ Department of Atmospheric and Earth Science, Severe Weather Institute-Radar and Lightning Laboratories, University of \\ Alabama in Huntsville, Huntsville, Alabama
}

(Manuscript received 10 June 2019, in final form 9 January 2020)

\begin{abstract}
The Sand Mountain and Lookout Mountain Plateaus in northeastern Alabama have been established as a regional relative maximum in tornadogenesis reports within the southeastern United States. Investigation of long-term surface datasets has revealed (i) stronger and more backed winds atop Sand Mountain than over the Tennessee Valley, and (ii) measured cloud-base heights are lower to the surface atop Sand Mountain than over the Tennessee Valley. These observations suggest that low-level wind shear and lifting condensation level (LCL) height changes may lead to conditions more favorable for tornadogenesis atop the plateaus than over the Tennessee Valley. However, prior to fall 2016, no intensive observations had been made to further investigate low-level flow or thermodynamic changes in the topography of northeastern Alabama. This paper provides detailed analysis of observations gathered during VORTEX-SE field campaign cases from fall 2016 through spring 2019. These observations indicate that downslope winds form along the northwest edge of Sand Mountain in at least some severe storm environments in northeastern Alabama. Wind profiles gathered across northeastern Alabama indicate that low-level helicity changes can be substantial over small distances across different areas of the topographic system. LCL height changes often scale to changes in land elevation, which can be on the order of 200-300 m across northeastern Alabama.
\end{abstract}

\section{Introduction}

The southeastern United States is a region particularly vulnerable to tornadoes due to both meteorological and societal factors. For example, long-tracked, significant tornadoes are common across the Southeast (Coleman and Dixon 2014). In addition, societal factors such as significant population density and built environment development (Ashley and Strader 2016), mobile home concentration (Strader and Ashley 2018), and a tendency for nocturnal tornado activity (Ashley et al. 2008; Kis and Straka 2010; Krocak and Brooks 2018) all lead to the Southeast being the most vulnerable region of the United States to tornado fatalities (Ashley 2007).

Corresponding author: Anthony W. Lyza, lyzaa@nsstc.uah.edu
The Verification of the Origins of Rotation in Tornadoes Experiment-Southeast (VORTEX-SE) was initiated in 2016 to investigate the unique physical and societal impact problems posed by tornadoes in the Southeast (NSSL 2019).

Investigation of the roles that terrain may play in the evolution of tornadic storms represents one focus of VORTEX-SE. The Sand Mountain and Lookout Mountain Plateaus served as a particular focus for investigation during field campaign activities from fall 2016 through fall 2018. These plateaus are hereafter referred to as the Southern Cumberland System (SCS) since they constitute the southern extent of the broader Cumberland Plateau terrain system. Lyza and Knupp (2018; hereafter LK18) showed that the SCS coincides with a regional, relative statistical maximum in tornadogenesis reports 


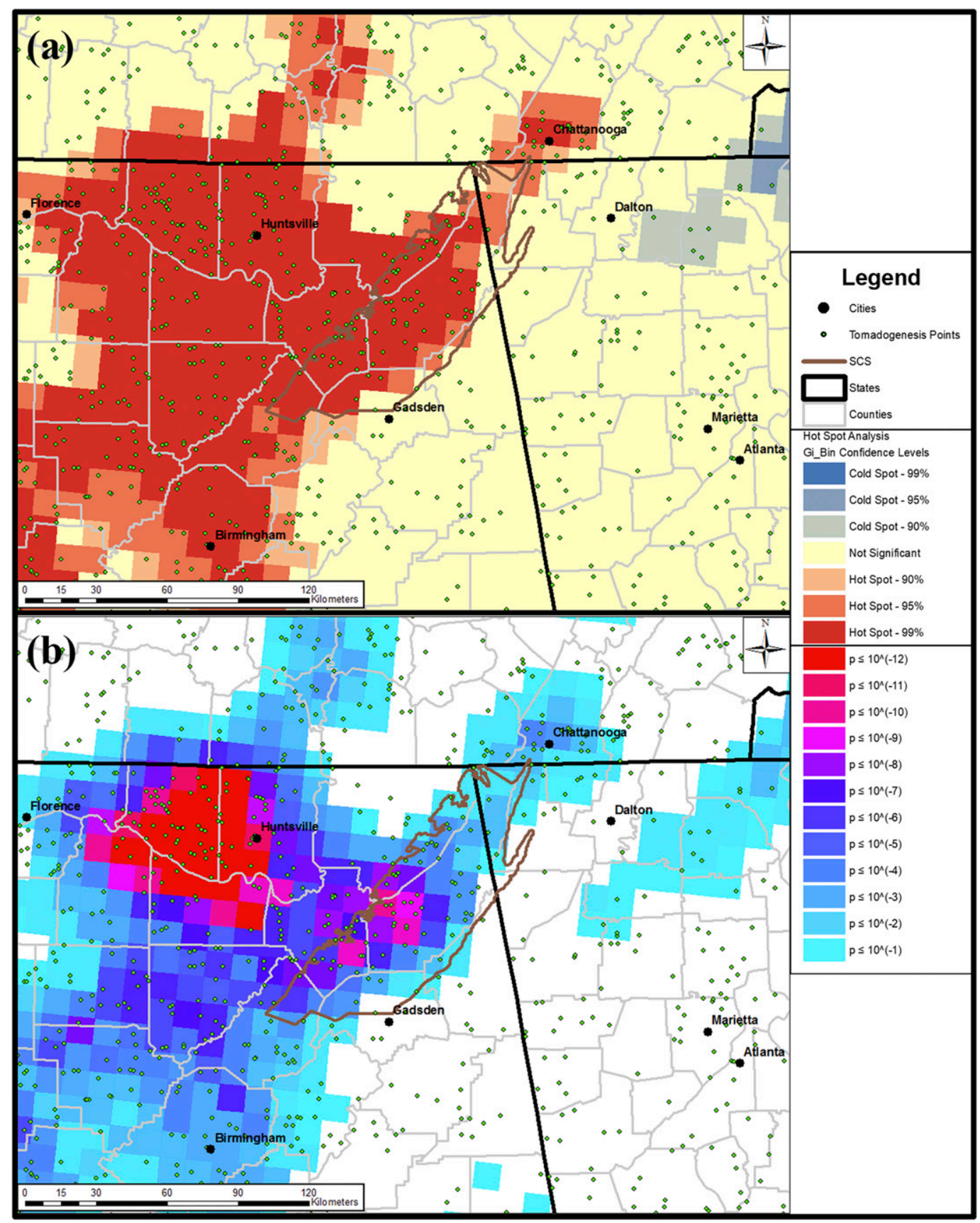

FIG. 1. Figure 4 from LK18, showing (a) an optimized hot spot analysis for tornadogenesis reports within $250 \mathrm{~km}$ of the SCS from the period 1992-2016 at 90\%, 95\%, and 99\% confidence levels, and (b) the $p$ values associated with each pixel. (Copyright American Meteorological Society. Used with permission.)

for the period from 1992 to 2016 and for a region within $250-\mathrm{km}$ distance of the SCS (Fig. 1). Analysis of long-term surface observation datasets from SCS tornado events and upstream Rapid Update Cycle (RUC)/Rapid Refresh (RAP) model soundings led to the development of two primary hypotheses expounded by LK18:
1) Upstream Froude number values (e.g., Hunt et al. 1988; Stull 1988; Vosper et al. 2002) support the acceleration of the southeasterly component of the low-level flow over the plateaus until reaching a maximum along the downslope gradient on the northwestern edge of Sand Mountain, in the shortaxis direction of the terrain (perpendicular to the 
major axis of the plateaus). With the major axis of the SCS oriented approximately from $218^{\circ}$ to $38^{\circ}$, such an acceleration would lead to stronger and more backed low-level flow across the SCS given southerly low-level flow in a severe storm environment, potentially increasing the magnitude of storm-relative helicity (SRH; Davies-Jones 1984) atop the plateaus.

2) Given the $150-300 \mathrm{~m}$ relief of the SCS over surrounding areas, the low-level thermodynamic environment may tend to be more supportive for tornadogenesis atop the SCS than in the adjacent Tennessee Valley, through reduction of LCL heights.

LK18 detailed evidence that surface winds tend to be stronger and more backed atop Sand Mountain than in the adjacent Tennessee Valley, and that a maximum in surface wind magnitude has been observed along the northwestern edge of Sand Mountain. Long-term surface observations from both atop Sand Mountain and within the Tennessee Valley presented in LK18 suggest that cloud-base heights relative to ground level tend to differ in approximate inverse proportion with the change in land elevation (e.g., a 50-m increase in land elevation between two observation sites would lead to cloud-base height being approximately $50 \mathrm{~m}$ closer to the ground at the higher-elevation site). Using these cloud-base height observations as a proxy for lifting condensation level (LCL) height would imply that LCL heights would tend to be lower atop the SCS than in the adjacent Tennessee Valley. Tornadogenesis potential generally increases with decreasing environmental LCL height through the decrease of negative buoyancy of rear-flank downdrafts (RFDs) in supercells (due to less subcloud evaporation), which subsequently aides the stretching of near-surface vertical vorticity (Rasmussen and Blanchard 1998; Markowski et al. 2002). In the Rasmussen and Blanchard (1998) dataset, the difference between the median LCL heights for nontornadic or weakly tornadic (F0-F1) supercells $(1230 \mathrm{~m})$ and significantly tornadic $(\mathrm{F} 2+)$ supercells $(780 \mathrm{~m})$ was $450 \mathrm{~m}$, illustrating how substantial an LCL height change of 200-300 m may be in influencing the potential for tornadogenesis.

This paper serves to investigate data gathered from VORTEX-SE across the SCS region from fall 2016 through spring 2019 to test these two hypotheses. In particular, observations from VORTEX-SE are analyzed to address two distinct sets of research questions related to the above hypotheses:

1) How do the low-level wind profiles vary across the SCS? Does a downslope wind enhancement exist, and do variations in the wind profile between the
SCS and the adjacent Tennessee Valley substantially affect SRH and low-level convergence?

2) How does LCL height typically vary from valley to plateau?

Data sources, cases, and methodologies used to investigate these questions are explained in detail. The results of these analyses are summarized and a refined hypothesis for how the SCS may impact the nearstorm environment and tornadogenesis potential is developed.

\section{Data and methodology}

\section{a. Data sources}

Data analyzed in this study were obtained from in situ and ground-based remote sensing platforms during the VORTEX-SE field campaign. While many instruments and platforms were deployed, two instrument platforms from the University of Alabama in Huntsville (UAH) were ultimately utilized in these analyses:

1) The HALO Photonics Streamline Doppler wind lidar (DWL; HALO Photonics 2019) on the Mobile Doppler lidar and Sounding system (MoDLS); and

2) The Mobile Alabama X-band (MAX) polarimetric scanning radar, which features a $1^{\circ}$ beamwidth and 3.2-cm wavelength (Asefi-Najafabady et al. 2010).

Because of degraded sensitivity experienced from fall 2016 to early spring $2018,{ }^{1}$ the use of MAX was limited to observations in precipitation, principally on 19 March 2018 as described in section 2 b. In addition to the UAH instruments, data from the National Severe Storms Laboratory (NSSL) Collaborative Lower Atmospheric Mobile Profiling System-2 (CLAMPS-2) Halo Photonics DWL Streamline XR were analyzed for the 5 April 2017 case described below.

In addition to the platforms listed above, balloon soundings were available for all cases analyzed. The two primary sounding types were the InterMet iMet-1ABXN (InterMet 2019a) and iMet-4AB (InterMet 2019b) systems, and Windsond Radiosonde S-1 system (Windsond 2019). To reduce the noise associated with the Windsond wind profiles, the winds are reprocessed using the 3-s resolution GPS position data provided in the raw data

\footnotetext{
${ }^{1}$ After the radome was removed in March 2018, clear air performance was significantly increased. However, a very limited number of SCS deployments were made after removal of the radome, and clear air return on those dates was poor, owing to a lack of biological scatterers.
} 
TABLE 1. Summary of cases and instruments used to study the environment across the SCS. The numbers of the locations in column 3 correspond to the instruments listed in column 2.

\begin{tabular}{|c|c|c|c|}
\hline Date & Instruments utilized & $\begin{array}{l}\text { Balloon sounding } \\
\text { locations }\end{array}$ & $\begin{array}{l}\text { Balloon sounding times } \\
\text { [format: date/time (UTC)] }\end{array}$ \\
\hline \multirow[t]{2}{*}{30 Nov 2016} & 1) Balloon soundings (plateau) & 1) Powell & 1) $30 / 0828$ \\
\hline & 2) Balloon soundings (valley) & 2) SW Scottsboro & 2) $30 / 0816$ \\
\hline \multirow[t]{2}{*}{9 Feb 2017} & 1) Balloon soundings (plateau) & 1) NACC & 1) $09 / 0145$ \\
\hline & 2) Balloon soundings (valley) & 2) Hollywood & 2) $09 / 0145$ \\
\hline \multirow[t]{2}{*}{25 Mar 2017} & 1) Balloon soundings (plateau) & 1) NACC & 1) $25 / 1605,25 / 1700,25 / 1800,25 / 1900,25 / 2000$ \\
\hline & 2) Balloon soundings (valley) & 2) Hollywood & 2) $25 / 1601,25 / 1702,25 / 1759,25 / 1901,25 / 2003$ \\
\hline \multirow{3}{*}{ 27-28 Mar 2017} & 1) Balloon soundings (plateau) & 1) NACC & 1) $27 / 1459,27 / 1658,27 / 1859,27 / 1958,27 / 2158,27 / 2333$ \\
\hline & 2), 3) Balloon soundings (valley) & 2) Hollywood & 2) $27 / 1500,27 / 1700,27 / 1900,27 / 2200,27 / 2302$ \\
\hline & & 3) Woodville & 3) $27 / 2028$ \\
\hline \multirow[t]{2}{*}{ 30-31 Mar 2017} & 1) Balloon soundings (plateau) & 1) NACC & 1) $30 / 2151,31 / 0000$ \\
\hline & 2) Balloon soundings (valley) & 2) Hollywood & 2) $30 / 2147,30 / 0010$ \\
\hline \multirow[t]{2}{*}{3 Apr 2017} & 1) Balloon soundings (plateau) & 1) NACC & 1) $03 / 2000,03 / 2200$ \\
\hline & 2) Balloon soundings (valley) & 2) Hollywood & 2) $03 / 2000,03 / 2200$ \\
\hline \multirow[t]{2}{*}{ 5-6 Apr 2017} & $\begin{array}{l}\text { 1) MoDLS, balloon } \\
\text { soundings (plateau) }\end{array}$ & 1) NACC & $\begin{array}{l}\text { 1) } 05 / 1130,05 / 1400,05 / 1600,05 / 1715,05 / 1900,05 / 2000 \text {, } \\
05 / 2220,05 / 2300\end{array}$ \\
\hline & $\begin{array}{l}\text { 2) CLAMPS-2, balloon } \\
\text { soundings (valley) }\end{array}$ & 2) Hollywood & $\begin{array}{l}\text { 2) } 05 / 1105,05 / 1349,05 / 1546,05 / 1702,05 / 1910,05 / 1950 \text {, } \\
05 / 2150,05 / 2248\end{array}$ \\
\hline \multirow[t]{2}{*}{22 Apr 2017} & 1) Balloon soundings (plateau) & 1) NACC & 1) $22 / 2134,22 / 2224$ \\
\hline & 2) Balloon soundings (valley) & 2) Hollywood & 2) $22 / 2131,22 / 2223$ \\
\hline \multirow[t]{2}{*}{30 Apr-1 May 2017} & 1) Balloon soundings (plateau) & 1) NACC & 1) $30 / 1700,30 / 1800,30 / 1900,30 / 2000,01 / 0000,01 / 0300$ \\
\hline & 2) Balloon soundings (valley) & 2) Hollywood & 2) $30 / 1650,30 / 1754,30 / 1851,30 / 1954,30 / 2349,01 / 0248$ \\
\hline \multirow[t]{4}{*}{ 19-20 Mar 2018} & 1) $M A X$ & 1) Sylvania & 1) $19 / 2358$ \\
\hline & 2) Balloon soundings (plateau) & 2) NACC & 2) $20 / 0000$ \\
\hline & 3) Balloon soundings (valley) & 3) Hollywood & \\
\hline & 4) $\mathrm{M} 3 \mathrm{~V}$ & 4) Roaming & \\
\hline \multirow[t]{3}{*}{6 Nov 2018} & $\begin{array}{l}\text { 1) MAX, balloon } \\
\text { soundings (plateaus) }\end{array}$ & 1) Grove Oak & 1) $06 / 0230,06 / 0630,06 / 0730$ \\
\hline & $\begin{array}{l}\text { 2) MoDLS, balloon soundings } \\
\text { (base of Sand Mountain) }\end{array}$ & $\begin{array}{l}\text { 2) Scottsboro } \\
\text { boat launch }\end{array}$ & 2) $06 / 0230,06 / 0630,06 / 0730$ \\
\hline & 3) $\mathrm{M} 3 \mathrm{~V}$, balloon soundings & 3) Roaming & 3) $06 / 0730$ \\
\hline \multirow[t]{2}{*}{ 14-15 Mar 2019} & 1) Balloon soundings (plateaus) & 1) NACC & 1) $14 / 1900,14 / 2000,14 / 2100,14 / 2200,14 / 2300,15 / 0100$ \\
\hline & 2) Balloon soundings (valley) & 2) Hollywood & 2) $14 / 1900,14 / 2000,14 / 2100,14 / 2200,14 / 2300,15 / 0100$ \\
\hline
\end{tabular}

files, as opposed to the raw 1-s resolution wind data, which contain significant nonmeteorological noise likely owing to oscillatory motion of the radiosonde package and attendant string connecting the package to the balloon.

\section{b. Deployment methodology}

Deployments across the SCS were performed for 12 cases between November 2016 and March 2019 (Table 1). Northeast Alabama Community College (NACC) in Powell, Alabama, was the primary Sand Mountain deployment site for the MoDLS profiling instrumentation and balloon soundings (Fig. 2). In the Tennessee Valley, the Scottsboro Regional Airport (K4A6) in Scottsboro, Alabama, served as the primary location for the CLAMPS-2 profiling system, while a site located in nearby Hollywood, Alabama (approximately $20 \mathrm{~km}$ away at a direction of $347^{\circ}$ ), was used as the primary balloon sounding location, due to the necessity for clearance from the airport property. The initial primary goal of deployments across northeastern Alabama was to observe differences in the wind profiles and LCL heights between the SCS and the adjacent Tennessee Valley. MoDLS and CLAMPS-2 were deployed to their semipermanent locations for cases during the 2017 VORTEX-SE campaign. All deployment locations used are summarized in Table 1 and Fig. 2. The MoDLS and CLAMPS-2 DWLs collected 1-Hz vertically pointing measurements of several minutes duration, interlaced with eight-point velocity-azimuth display profiles (VADs) at a $60^{\circ}$ elevation angle, with MoDLS operating at a 42-m gate spacing and CLAMPS-2 operating at a 26-m gate spacing for the 5 April 2017 case detailed in this paper. To create the VAD wind profiles, a best-fit cosine curve was fitted to the Doppler velocity profiles from each of the eight beams per scan. In all, seven of the 11 SCS deployments utilized in this paper occurred during the VORTEX-SE 2017 field campaign.

For the 2016 and 2017 cases, most data collection focused on assessing the differences in low-level wind and 


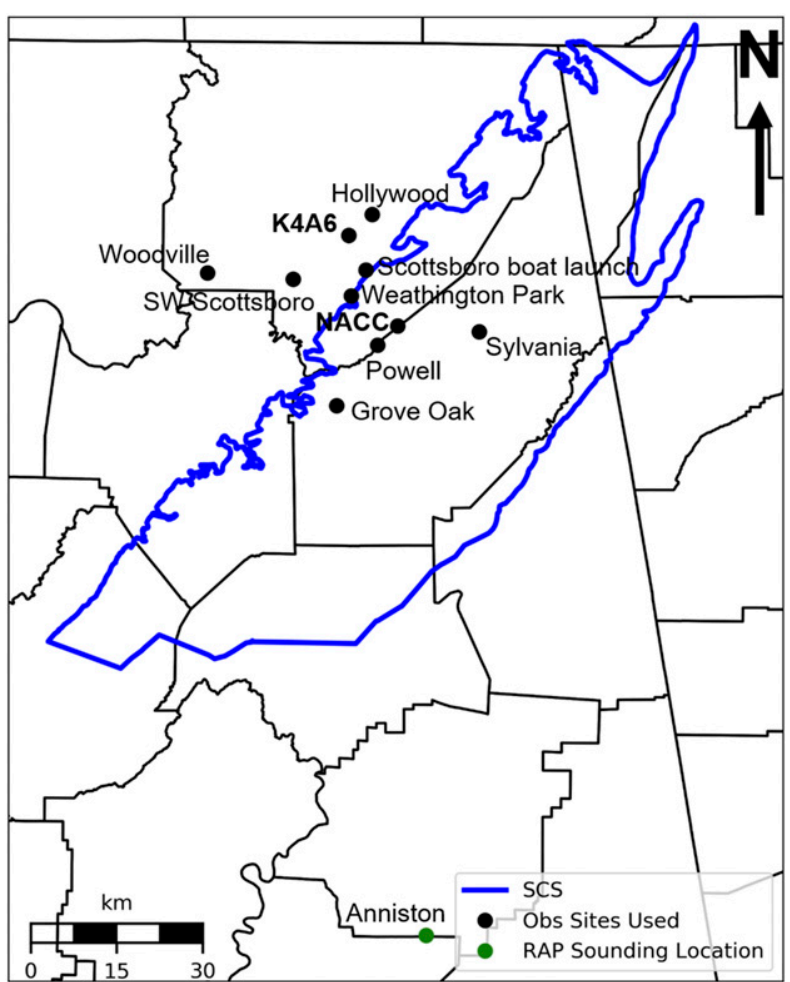

FIG. 2. Overview map of deployment locations for operations studying the SCS that are utilized in this manuscript. The locations of MoDLS (NACC) and CLAMPS-2 (K4A6) during the VORTEX-SE 2017 field campaign are bolded. Upstream RAP/RUC soundings were obtained from the Anniston location.

thermodynamic profiles between the surface of Sand Mountain and the Tennessee Valley, across the river and removed from the base of Sand Mountain. Most data analyses were performed on sounding and profiler datasets acquired from NACC and K4A6/Hollywood, as these two sites contain the most thorough collection of observations across numerous deployments. Soundings gathered at NACC and Hollywood during the deployments were temporally coordinated in an attempt to match LCL height values and assess consistency in differences between LCL heights and $0-1 \mathrm{~km}$ SRH atop the plateau against those in the Tennessee Valley. For 5 April 2017, the $0-1 \mathrm{~km}$ SRH time series from MoDLS at NACC and CLAMPS-2 at K4A6 were also compared to assess their evolution prior to storm arrival.

Deployments in 2018 and 2019 focused more on the potential development of a downslope wind enhancement and the effects such an enhancement may have on the wind shear profiles across Sand Mountain. For the 19-20 March 2018 and 14-15 March 2019 deployments, soundings were still gathered at both NACC and Hollywood for comparison. For each of these cases, the MAX radar was deployed to Sylvania, Alabama, with the primary goal of collecting range-height indicator (RHI) data of the variation in horizontal flow across the 22-km distance from the windward side of Sand Mountain to the northwestern slope and the adjacent Tennessee Valley. On 6 November 2018, MoDLS was deployed to a boat launch near Scottsboro along the Tennessee River, directly at the base of the northwestern slope of Sand Mountain. MoDLS was placed at this location to facilitate direct detection of the potential downslope wind enhancement. MAX was placed at the Grove Oak site atop Sand Mountain. Soundings were collected from the MAX site at Grove Oak (atop Sand Mountain), from MoDLS at the base of Sand Mountain, and from the UAH Mobile Meteorological Measurements Vehicle (M3V), a mobile mesonet which roamed atop and upwind Sand Mountain. No soundings were performed farther out across the valley at Hollywood.

Background characteristics for each deployment case are provided in Table 2. Only three of the 12 cases featured tornadoes on the SCS: 29-30 November 2016, 22 April 2017, and 19 March 2018. In all three cases, supercells were the primary storm mode. Most cases featured weak to moderate mixed-layer convective available potential energy (MLCAPE), with values remaining below $2000 \mathrm{~J} \mathrm{~kg}^{-1}$ for all cases except for 5 April 2017. Surface layer to lower boundary layer flow was generally southerly across deployment cases, with surface- $250 \mathrm{~m}$ mean wind directions ranging from $128^{\circ}$ to $208^{\circ}$, and surface $-250 \mathrm{~m}$ mean wind speeds of 3.1 to $11.5 \mathrm{~m} \mathrm{~s}^{-1}$. The surface- $250 \mathrm{~m}$ static stability ranged from absolutely stable inversions to absolutely unstable (superadiabatic lapse rates).

\section{c. Data analysis}

Once data collected were assessed for their quality by ensuring no erroneous wind data (extreme outlier values within the profile) or periods of balloon descent, analyses were performed to evaluate changes in the environment at different points across Sand Mountain and the Tennessee Valley. Simple linear regression analyses were performed between coordinated balloon launches at sites around NACC/Powell and Scottsboro/Hollywood ${ }^{2}$ (excluding the boat dock at the base of Sand Mountain) to compare the relationships between LCL height and 0-1 km SRH changes between the Tennessee Valley and Sand Mountain, using data from all cases listed in Table 1 except for 6 November 2018. These 10 cases yield 40 pairs of soundings between the two locations

\footnotetext{
${ }^{2}$ All sites used in this comparison featured elevation changes of $1 \mathrm{~m}$ MSL or less between the different valley sites or plateau sites, respectively.
} 
TABLE 2. Summary of storm mode, SCS tornado occurrence, storm motion, 0-250 m temperature lapse rate, $0-250 \mathrm{~m}$ mean wind direction, 0-250 m mean wind speed, and mixed-layer CAPE (MLCAPE) for the cases described in Table 1. Storm modes were classified as supercell, quasi-linear convective system (QLCS), other (for less organized convection), or none (for cases with no SCS deep convection). The $0-250 \mathrm{~m}$ and MLCAPE values are ranges of values from upstream soundings at Anniston that were used to compare to paired soundings described section $2 \mathrm{~b}$ (events with one value only featured one paired sounding).

\begin{tabular}{|c|c|c|c|c|c|c|c|}
\hline Date (UTC) & $\begin{array}{c}\text { Primary } \\
\text { storm mode }\end{array}$ & $\begin{array}{l}\text { Tornadoes } \\
\text { on SCS }\end{array}$ & $\begin{array}{l}\text { Storm motion } \\
\left({ }^{\circ}, \mathrm{m} \mathrm{s}^{-1}\right)\end{array}$ & $\begin{array}{c}0-250 \mathrm{~m} T \text { lapse } \\
\text { rate }\left({ }^{\circ} \mathrm{C} \mathrm{km}^{-1}\right)\end{array}$ & $\begin{array}{c}0-250 \mathrm{~m} \text { mean } \\
\text { wind direction }\left(^{\circ}\right)\end{array}$ & $\begin{array}{c}0-250 \mathrm{~m} \text { mean } \\
\text { wind speed } \\
\left(\mathrm{m} \mathrm{s}^{-1}\right)\end{array}$ & $\begin{array}{c}\text { MLCAPE } \\
\left(\mathrm{J} \mathrm{kg}^{-1}\right)\end{array}$ \\
\hline 30 Nov 2016 & Supercell & $2(\mathrm{EF} 1, \mathrm{EF} 3)$ & $239,24.2$ & -7.0 & 172 & 7.5 & 999 \\
\hline 9 Feb 2017 & Supercell & None & $275,21.1$ & 5.7 & 183 & 3.6 & 909 \\
\hline 25 Mar 2017 & Other & None & $196,13.4$ & -13.3 to -15.1 & 151 to 160 & 6.0 to 7.8 & 0 to 510 \\
\hline 27 Mar 2017 & Mixed & None & $270,14.9$ & 0.6 to -15.9 & 171 to 201 & 3.3 to 7.0 & 933 to 1711 \\
\hline 30-31 Mar 2017 & Other & None & $204,17.5$ & -4.4 to -9.0 & 192 to 208 & 7.7 to 8.6 & 369 to 822 \\
\hline 3 Apr 2017 & None & None & $250,15.4$ & -8.3 to -12.8 & 176 to 187 & 9.3 to 11.5 & 107 to 114 \\
\hline 5-6 Apr 2017 & QLCS & None $^{a}$ & $241,14.9$ & 1.3 to -8.8 & 153 to 203 & 3.1 to 8.0 & 365 to 3381 \\
\hline 22 Apr 2017 & Supercell & $1(\mathrm{EF} 0)$ & $280,15.4$ & -8.7 to -11.9 & 203 to 208 & 5.8 to 7.4 & 447 to 705 \\
\hline 30 Apr-1 May 2017 & QLCS & None & $225,18.0$ & 4.4 to -14.4 & 140 to 206 & 3.9 to 7.3 & 78 to 1343 \\
\hline 19-20 Mar 2018 & Supercell & 1 (EF2) & $281,19.0$ & -5.1 & 128 & 5.6 & 1740 \\
\hline 6 Nov 2018 & Mixed & None & $257,23.7$ & -8.9 & 178 & 8.6 & 972 \\
\hline 14-15 Mar 2019 & Supercell & None & $241,15.4$ & -1.9 to -15.9 & 156 to 173 & 6.7 to 8.4 & 57 to 655 \\
\hline
\end{tabular}

${ }^{a}$ While no tornado was recorded on the SCS, a circulation that formed near the northern tip of Sand Mountain did produce an EF0 tornado just north of the SCS (Lyza and Knupp 2017).

that were included in the initial regression analyses. For SRH calculations, a three-point boxcar average was applied to the lowest $1 \mathrm{~km}$ of every sounding wind profile to further reduce noise in the shear vectors. Final regression analyses presented were developed by excluding outlier data points when appropriate. Outliers were defined as data points that fell outside of 1.5 times the interquartile range of the values for a given variable.

To better understand how observed changes in SRH may be related to the broader flow regime around the SCS, the 40 sounding pairs described in section $2 \mathrm{~b}$ were compared to upstream RAP model soundings ${ }^{3}$ from Anniston, Alabama, to assess the upstream Froude number in the cases with paired sounding observations. The use of RUC and RAP soundings does introduce some potential error to the analysis. Benjamin et al. (2016) showed that the RAP contained root-meansquare (RMS) errors of approximately 2.6 to $3.1 \mathrm{~m} \mathrm{~s}^{-1}$ in wind speed and $0.8^{\circ}$ to $1.0^{\circ} \mathrm{C}$ in temperature at analysis time for the time period from May 2013 through November 2014. Errors in both wind speed and temperature could adversely impact calculations of the Froude number from the RUC/RAP soundings. The forms of the Froude number used in this analysis are those used in LK18 and are defined as $\mathrm{Fr}_{H}=U /(N H)$ and $\mathrm{Fr}_{L}=(U \pi) /(N L)$, where $U$ is the terrain-perpendicular component of the wind, $N$ is the Brunt-Väisälä frequency,

\footnotetext{
${ }^{3}$ RAP soundings were used because very few cases included upstream observed soundings.
}

$H$ is the depth of the obstruction, $L$ is the width of the obstruction, and $U$ and $N$ are calculated as mean values over the depth of the obstruction from a point upwind. Zero-hour forecast soundings from at least $45 \mathrm{~min}$ prior to each pair of observed soundings were used in order to allow for parcels to be advected over the plateaus. Because the focus is on the change in flow atop the plateau surface, as opposed to along the leeward slope, $\mathrm{Fr}_{H}$ was used in this analysis.

\section{Observations}

\section{a. Low-level wind profile modifications}

\section{1) OBSERVATIONS OF DOWNSLOPE WIND ENHANCEMENT ALONG THE NORTHWEST SIDE OF SAND MOUNTAIN}

As discussed in LK18, one subject of particular observational interest within the SCS is the potential for a low-level wind maximum to form along the northwestern edge of Sand Mountain. Froude number calculations from upstream RUC and RAP soundings before tornado events in the SCS have indicated values favorable for acceleration of low-level flow over the plateaus, reaching a maximum on the leeward (northwestern) side of Sand Mountain. Long-term surface observations from automatic weather observing stations (AWOSs) in northeastern Alabama lend some support to this hypothesis, with surface winds persistently more backed and stronger atop Sand Mountain than in the adjacent Tennessee Valley (LK18). 

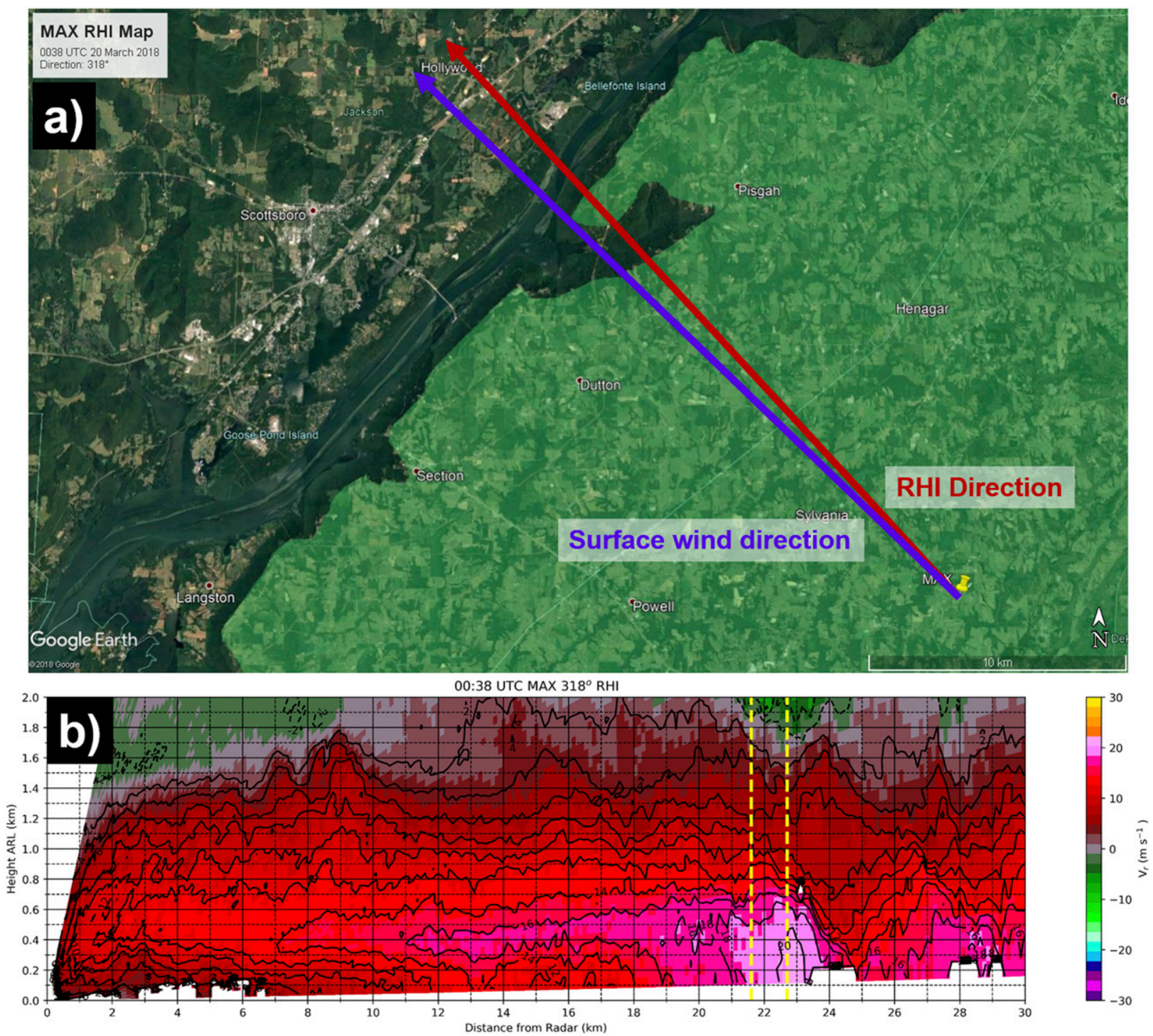

FIG. 3. (a) Map illustrating the location of MAX at Sylvania (see Fig. 2 for location), the direction of the $318^{\circ}$ RHI at 0038 UTC 20 Mar 2018, and the approximate surface wind direction atop Sand Mountain. The area atop Sand Mountain is highlighted in green. (b) MAX RHI scan of base radial velocity $\left(V_{r}\right)$ pointed at $318^{\circ}$ from the Sylvania, AL, site at 0038 UTC 20 Mar 2018. The approximate location of the northwestern slope of Sand Mountain is between the yellow dashed lines. Isodops of radial velocity are provided in black (solid-positive, dashed-negative) every $2 \mathrm{~m} \mathrm{~s}^{-1}$, beginning at $\pm 2 \mathrm{~m} \mathrm{~s}^{-1}$.

To test this hypothesis, observations focusing on the northwestern edge of Sand Mountain were gathered on 19-20 March 2018 and 6 November 2018. The requirement for coordinated scanning strategies with other mobile radars led to only a small number of MAX RHI scans during the 19-20 March event. However, the RHI scans that were collected from MAX atop Sand Mountain pointing toward and roughly perpendicular to the leeward edge of the plateau indicate an intense acceleration of the terrain-perpendicular component of the flow across the plateau (Fig. 3). Radial velocity $\left(V_{r}\right)$ values between 200 and $300 \mathrm{~m}$ above radar level
(ARL) vary from 6 to $7 \mathrm{~m} \mathrm{~s}^{-1}$ near the MAX location to over $20 \mathrm{~m} \mathrm{~s}^{-1}$ along the edge of the plateau and over the Tennessee River before restoring to weaker values farther to the northwest over the valley. In all RHIs, the observed acceleration was confined to heights below $1 \mathrm{~km}$ ARL, with most of the acceleration observed limited to below $750 \mathrm{~m}$ ARL. This acceleration may represent an extreme example, however, due to the near-surface stability observed atop the plateau (Fig. 4).

To further investigate this wind acceleration, including the magnitude of the downward wind component, MoDLS was located directly at the base of the leeward 


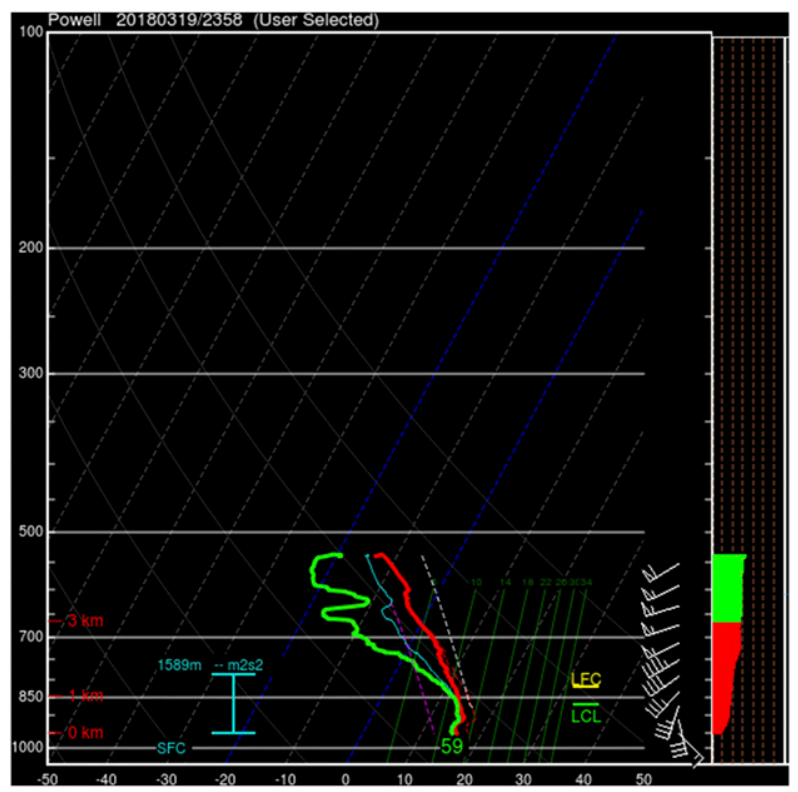

FIG. 4. Sounding launched at 2358 UTC 19 Mar 2018 from NACC. Image produced using SHARPpy (Blumberg et al. 2017).

slope of Sand Mountain on 5-6 November 2018, at a location where the land elevation of Sand Mountain is approximately $200 \mathrm{~m}$ higher than the elevation of the Tennessee River. The 5-6 November event consisted of a severe quasi-linear convective system (QLCS) that produced several tornadoes across northeastern Mississippi, northern Alabama, and southern middle Tennessee, including an EF1 that tracked from 14 to $7 \mathrm{~km}$ southwest of Scottsboro (NCEI 2019). The environment ahead of the QLCS was characterized by southerly low-level flow and very strong low-level vertical wind shear. Vertical stare data from the MoDLS DWL indicated persistent downward vertical motion of approximately $1-3 \mathrm{~m} \mathrm{~s}^{-1}$ below $600 \mathrm{~m}$ AGL prior to the arrival of precipitation, with a slight tendency toward weaker downward motion during the night (Fig. 5). Ascent rate information from the soundings launched at the MoDLS site also appears to support the idea of persistent, substantial downward vertical motion along the lee of Sand Mountain. Ascent rates on all five soundings experienced a substantial decrease, slowing by $1.5 \mathrm{~m} \mathrm{~s}^{-1}$ to as much as $4.5 \mathrm{~m} \mathrm{~s}^{-1}$ between 150 and $300 \mathrm{~m}$ AGL Fig. 6). Furthermore, the potential temperature $(\theta)$ profiles from the soundings launched at MoDLS indicate sharp vertical gradients in $\theta$ that are not found on soundings launched from MAX or M3V atop Sand Mountain and would be consistent with the development of a downslope wind enhancement (e.g., Klemp and Lilly 1975; Fig. 7), where the isentropes are good approximations of streamlines for steady, adiabatic flow. Thus, the sharp vertical change in $\theta$ observed in the soundings is indicative of a layer where vertical isentropes are being packed, which would be analogous to the packing of streamlines and the acceleration of flow.

Significant cloud cover limited the vertical range of observations from the MoDLS DWL (generally limited to approximately $600 \mathrm{~m}$ AGL, or the approximate height of cloud base over MoDLS), and a lack of clear air targets precluded MAX VADs reaching $1 \mathrm{~km}$ AGL. Therefore, the hodographs from paired sounding launches between MAX and MoDLS at 0230, 0630, and 0730 UTC were analyzed to assess how the downslope wind enhancement might affect the low-level wind shear profile. In comparing the balloon sounding observations, the $0-1 \mathrm{~km}$ AGL SRH was persistently much greater at the MoDLS site at the base of Sand Mountain than from either the MAX site or from M3V atop Sand Mountain (Fig. 8). The implications of this observed change in SRH are discussed in section 4 .

\section{2) LOW-LEVEL WIND SHEAR ENHANCEMENT ATOP SAND MOUNTAIN}

The 19 March 2018 and 5-6 November 2018 cases show clear signs that a downslope wind enhancement can form on the northwestern (leeward) edge of Sand Mountain. The data from 5 to 6 November 2018 show that SRH can be substantially higher near the base of Sand Mountain, but many storms do not reside along the slope or above of immediate base of the plateau for long periods of time. Additionally, potentially deleterious effects of the downslope wind enhancement on storm strength are evident, including the presence of a layer of higher static stability and persistent downward vertical motion. The stronger static stability could serve to limit parcels from below the stable layer from being ingested into the updraft. Meanwhile, the persistent downward vertical motion could theoretically act as a sink to vertical vorticity stretching, which would act to counter the effects of increased streamwise vorticity ingestion inferred by the increase in SRH. A more pressing question, therefore, is how the horizontal component of this acceleration and horizontal acceleration of parcels over the plateaus themselves may impact the low-level wind shear profile in the near-storm environment of storms as they reach the plateau. The RHI observations from 19 March 2018 (Fig. 3b) indicate that the acceleration of the horizontal wind into the downslope wind enhancement can extend substantially upstream over the plateau, and the vertical profiles of $\theta$ on top of Sand Mountain from 5 to 6 November 2018 (Fig. 7), all of which were gathered within $12 \mathrm{~km}$ of the northwestern slope, show no evidence of the enhanced stability indicated by the soundings launched at the base of Sand Mountain. These observations combined indicate that the effects of the 

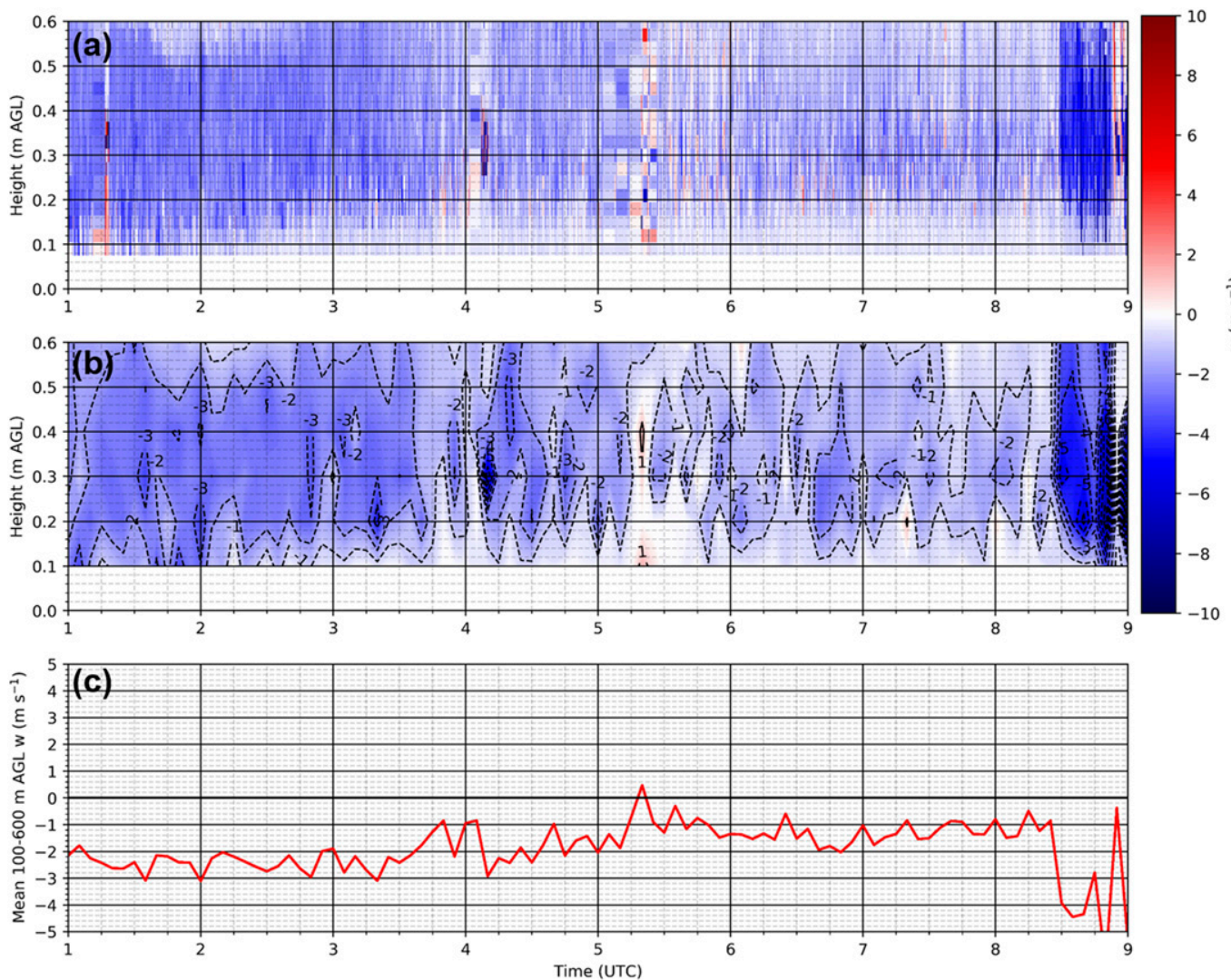

FIG. 5. MoDLS DWL vertical stare data of (a) raw vertical velocity (w), (b) $w$ interpolated every 5 min and $100 \mathrm{~m}$, and (c) mean interpolated $w$ between 100 and $600 \mathrm{~m}$ AGL between 0100 and 0900 UTC 6 Nov 2018 from the Scottsboro boat launch at the base of Sand Mountain.

downslope wind enhancement on storm evolution may be focused atop the Sand Mountain Plateau along the northwestern edge, particularly given that the typical southwesterly storm motion can result in storms residing within the northwesternmost 10-15 km of Sand Mountain for 15-20 min or more, but additional observations and numerical simulations will be necessary to resolve the total impact of the enhancement on storm evolution.

Given the variability of observational arrays utilized, the varying performance of remote sensing profilers, and a general dearth of environments representative of severe storm environments during the long-term profiling period of VORTEX-SE 2017, the dataset of balloon soundings discussed in section $2 \mathrm{~b}$ were the primary source utilized to study the variation of wind profiles between Sand Mountain and the Tennessee Valley. An initial analysis of these 40 pairs of soundings between NACC/Powell and Hollywood/Scottsboro indicates significant variability in $0-1 \mathrm{~km}$ SRH difference between the two sites, with a mean plateau-valley SRH change of $11.3 \mathrm{~m}^{2} \mathrm{~s}^{-2}$, a median difference of $-3.5 \mathrm{~m}^{2} \mathrm{~s}^{-2}$, and large boxes on the box-and-whisker plot (Fig. 9).
While this result would seem to refute the hypothesis that low-level wind shear and SRH tend to be higher atop Sand Mountain than in the Tennessee Valley, a closer look at the relationship between SRH in the Tennessee Valley and SRH atop Sand Mountain shows that may not necessarily be the case. When a linear regression is performed between SRH at the two locations, a tendency becomes evident for the plateau-valley SRH change to be more positive (SRH higher atop the plateau) as the mean SRH at both locations increases (Fig. 10). This tendency is further supported when the change in SRH is compared to the mean SRH between the two locations (Fig. 11), which reveals a moderately correlated, statistically significant linear regression relationship between the SRH change and the SRH mean values. The combination of the linear regression relationship and the number of data points with low values of mean $0-1 \mathrm{~km}$ SRH in Fig. 10 (22 of 40 data points with mean $0-1 \mathrm{~km}$ SRH values $<150 \mathrm{~m}^{2} \mathrm{~s}^{-2}$ ) indicates that the dominance of sounding pair data points in marginal, nontornadic environments may skew the interpretation of how SRH may differ from valley to plateau in tornadic environments. 

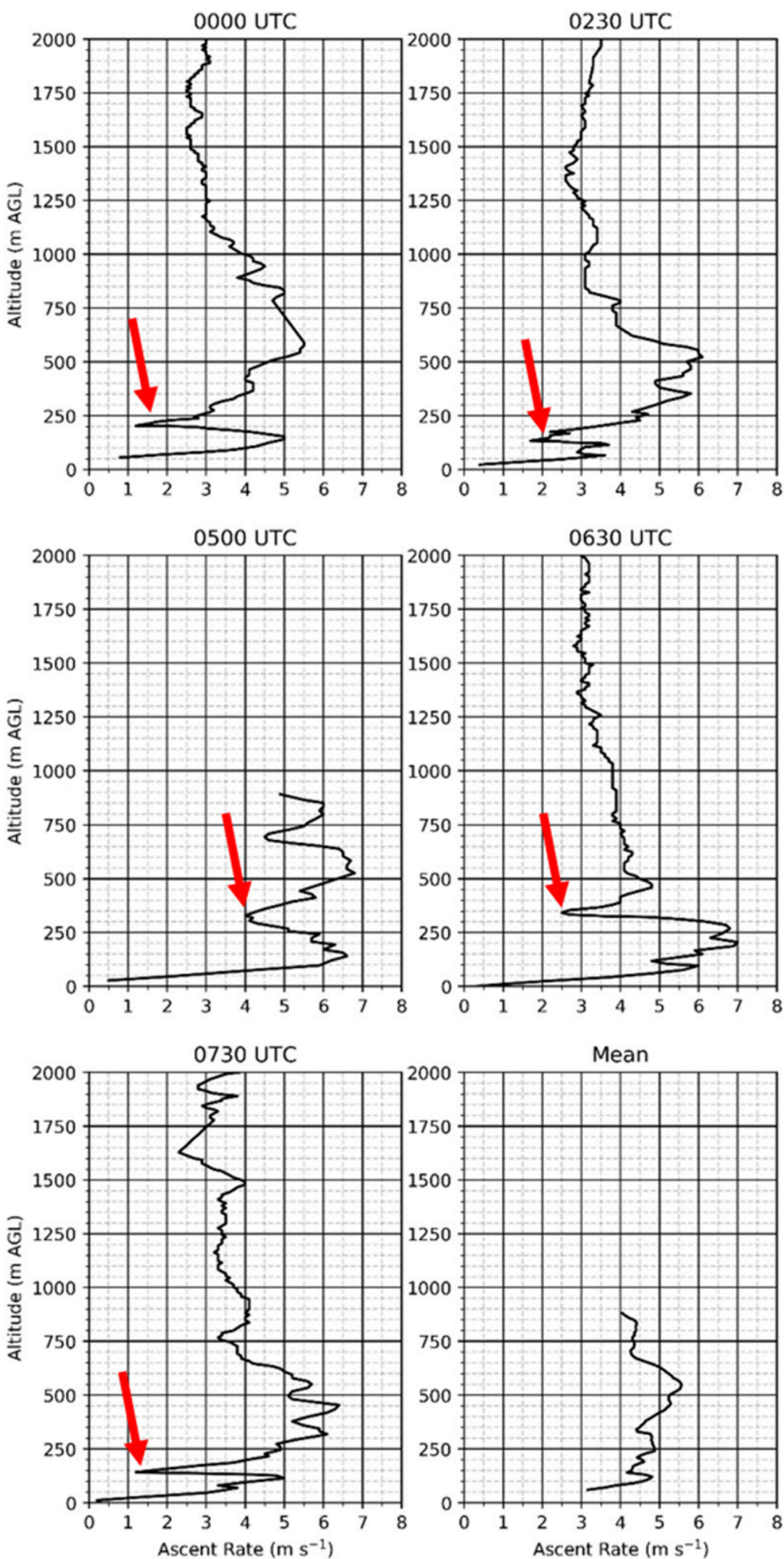

FIG. 6. Plots of ascent rate with height for all launches at the Scottsboro boat launch on 6 Nov 2018, and (bottom right) a plot of mean ascent rate for all balloons. The red arrows indicate the ascent rate minima associated with the downslope wind enhancement. 


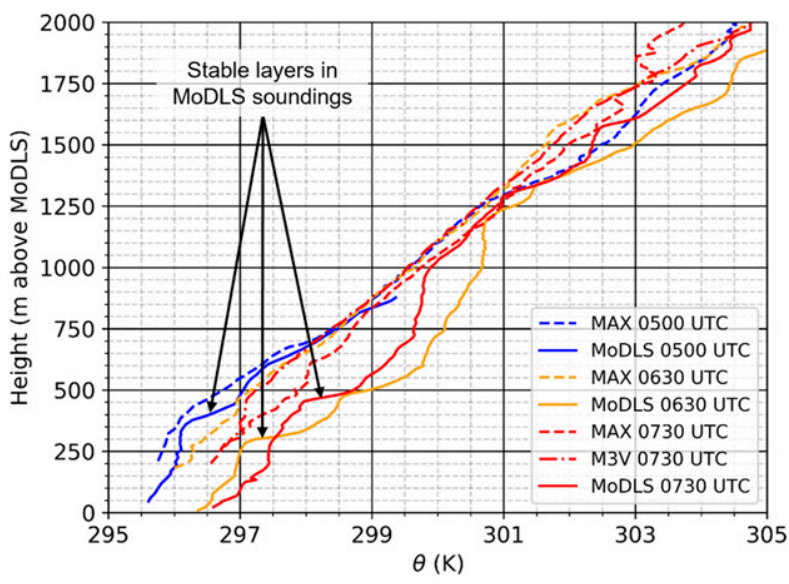

FIG. 7. Vertical profiles of potential temperature $(\theta)$ from soundings collected atop Sand Mountain (MAX and M3V) and in the Tennessee Valley (MoDLS) on 6 Nov 2018.

The tendency for SRH to be higher atop the plateau than in the valley with increasing overall SRH can be clearly seen from the 5 April 2017 dataset. Every balloon sounding from the morning hours indicates a higher SRH in the Tennessee Valley at Hollywood than on the Sand Mountain Plateau at NACC, with SRH values in the valley generally ranging between 50 and $100 \mathrm{~m}^{2} \mathrm{~s}^{-2}$ higher than atop the plateau (Fig. 12). During these morning hours, SRH magnitudes at the two sites generally ranged from around 0 to $100 \mathrm{~m}^{2} \mathrm{~s}^{-2}$. As the overall SRH increased during the afternoon hours, the tendency reversed, with higher SRH values at NACC than at Hollywood. This trend seen in the balloon sounding data is further supported by the CLAMPS- 2 and MoDLS DWLs at Scottsboro and NACC, respectively. Both lidars began retrieving VAD profiles at least $1-\mathrm{km}$ deep just after 2000 UTC, as the larger-scale SRH increase was ongoing and low clouds cleared out of the area. Although some noise in the $0-1 \mathrm{~km}$ SRH calculations is evident between VAD scans on each lidar, values are higher atop Sand Mountain than in the Tennessee Valley. Furthermore, the difference in SRH tends to be greater as the overall SRH peaks at $300-450 \mathrm{~m}^{2} \mathrm{~s}^{-2}$ between approximately 2130 and 2300 UTC (Fig. 12). Overall, the observations support the hypothesis that SRH tends to be higher atop the plateaus than in the valley in environments of large mean SRH, and higher in the valley than atop the plateau in environments of small mean SRH. The relationship between broader environmental tornadic favorability, the difference in SRH between valley and plateau, and possible physical explanations linking the effects of the plateau on the lowlevel flow to how SRH enhancement varies are discussed in section 4.

\section{b. LCL height changes}

In addition to wind profile modifications, LK18 addressed the potential for thermodynamic profile changes over the SCS. Long-term surface observations in tornadic environments have shown a general tendency for a decrease in LCL heights atop Sand Mountain versus those over the Tennessee Valley (LK18). Two primary outstanding questions that the dataset in LK18 cannot address, however, are 1) whether or not these LCL changes truly scale to the terrain elevation changes, leading to even greater LCL height differences in between areas where the relief in elevation is more pronounced, and 2) whether or not changes in LCL height from valley to plateau can have a meaningful effect on the cold pool characteristics of deep convection moving through the region.

The balloon sounding datasets collected across northeastern Alabama indicate that a clear difference in LCL height typically exists between the top of the SCS and the adjacent Tennessee Valley, an elevation change of approximately $200 \mathrm{~m}$. The 40 sounding pairs detailed in section $2 \mathrm{~b}$ show a mean decrease in mixed-layer (ML) LCL height of $84 \mathrm{~m}$ AGL from valley to plateau and a median decrease of $132 \mathrm{~m}$ AGL (Fig. 13). When the four outlier data points from Fig. 13 are removed, a strong linear correlation can be confirmed between LCL heights at NACC/Powell and Hollywood/Scottsboro $(r=0.96$, Fig. 14), and the mean and median LCL decrease from valley to plateau change to 128 and $137 \mathrm{~m} \mathrm{AGL}$, respectively. A total of 32 of 36 points in Fig. 14 are located to the left of the 1-1 line, indicating higher LCLs in the valley at Hollywood than atop Sand Mountain at NACC. The differences in how these observed LCL changes scale to the change in land elevation between the plateau and the valley are discussed in section 4 .

\section{Analysis and discussion}

The preliminary observations presented in this analysis generally support the hypotheses presented in section 1 as to how the near-storm environment of storms in northeastern Alabama may be affected by the SCS plateaus. Datasets gathered on 19 March 2018 and 5-6 November 2018 show clear evidence that low-level flow tends to accelerate over Sand Mountain, reaching a maximum in a downslope wind enhancement along the northwestern (leeward) edge. The enhancement of the lowlevel flow over the plateau in the terrain-perpendicular direction can be substantial. The terrain-perpendicular wind increased by nearly a factor of two to three below $500 \mathrm{~m}$ ARL across a distance of about $23 \mathrm{~km}$ from the MAX site atop Sand Mountain to the peak of the wind 

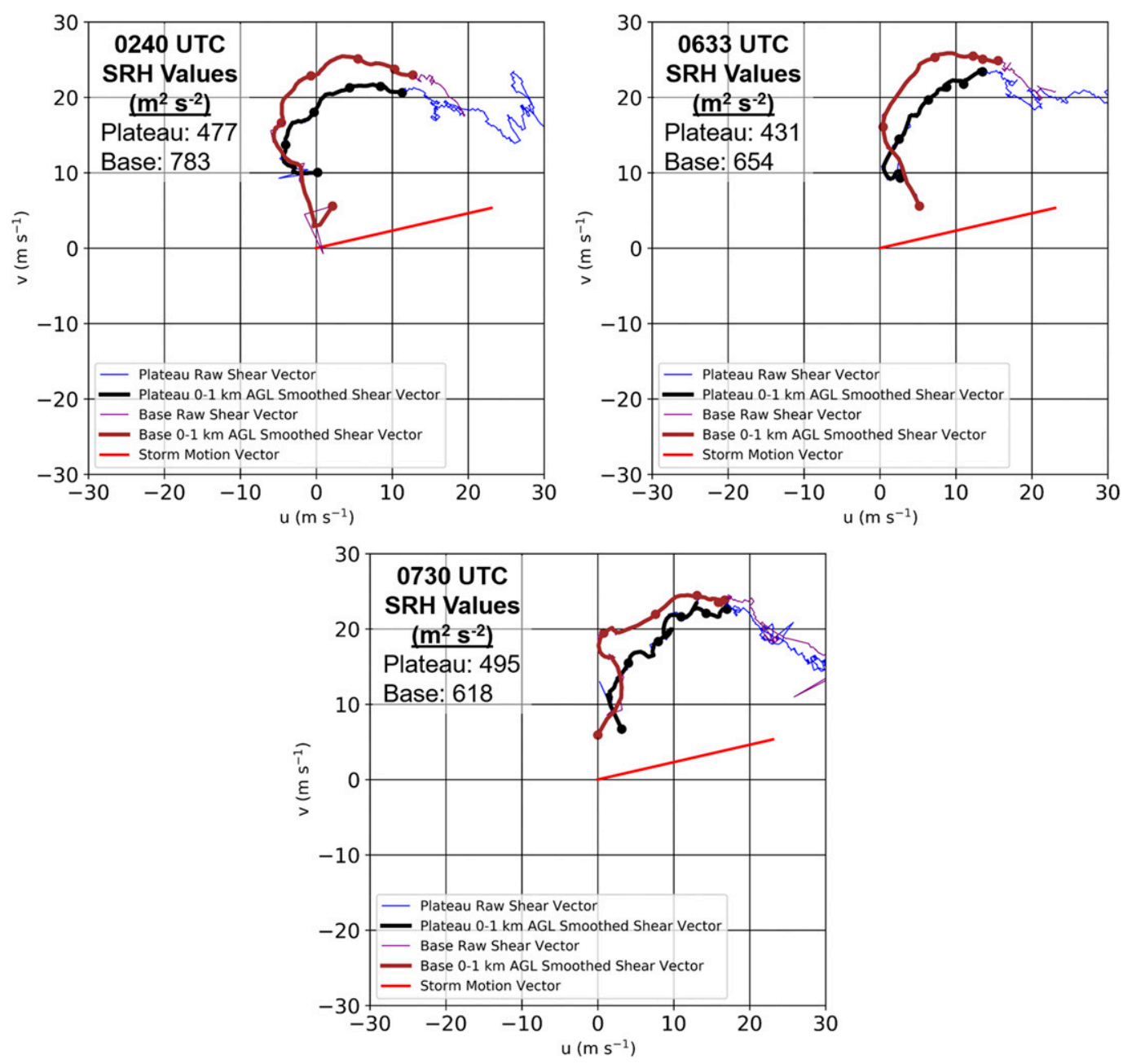

FIG. 8. Hodographs and 0-1 km SRH values from paired soundings launched at Grove Oak (plateau/black) and the Scottsboro boat launch (base/brown) on 6 Nov 2018. Dots on each 0-1 km smoothed shear vector indicate heights from the surface to $1 \mathrm{~km}$ AGL at 200-m intervals. Times listed are the average times between the two soundings. See Table 1 for exact sounding launch times.

enhancement over the Tennessee River before rapidly decreasing over the valley on the other side of the river from Sand Mountain. The 5-6 November 2018 dataset indicates that the downward vertical motion in this downslope enhancement may persistently reach a magnitude of $1-3 \mathrm{~m} \mathrm{~s}^{-1}$ in tornadic environments, ${ }^{4}$ and that $0-1 \mathrm{~km}$ AGL SRH can potentially be $25 \%-50 \%$ higher at the base of Sand Mountain than even atop the plateau.

The differences in low-level wind shear profiles from the surface atop Sand Mountain to the Tennessee Valley, however, are far more complicated. While the

\footnotetext{
${ }^{4}$ While no tornadoes occurred on the SCS during the 5-6 November 2018 event, an EF1 tornado did occur immediately across the Tennessee River from the SCS near Scottsboro, Alabama.
}

datasets of comparison soundings between Sand Mountain at NACC/Powell and the Tennessee Valley at Hollywood/Scottsboro do not indicate a clear preference for higher SRH atop Sand Mountain, the scatterplot of $\mathrm{SRH}$ at the two locations indicates that SRH enhancement atop the plateau may at least in part be related to an overall increase in SRH in the meso- $\beta$-scale environment. This relationship raises two questions, the answers to which could lend toward understanding of how and why wind profiles may be linked to the background environment and also serve to aid in operational utility of the findings in northeast Alabama.

The first question is whether or not the difference in SRH between the plateaus and the valley/surrounding areas is linked to the kinematic and thermodynamic characteristics of parcels upstream from the plateaus. To address this question, the $\mathrm{Fr}_{H}$ values computed 


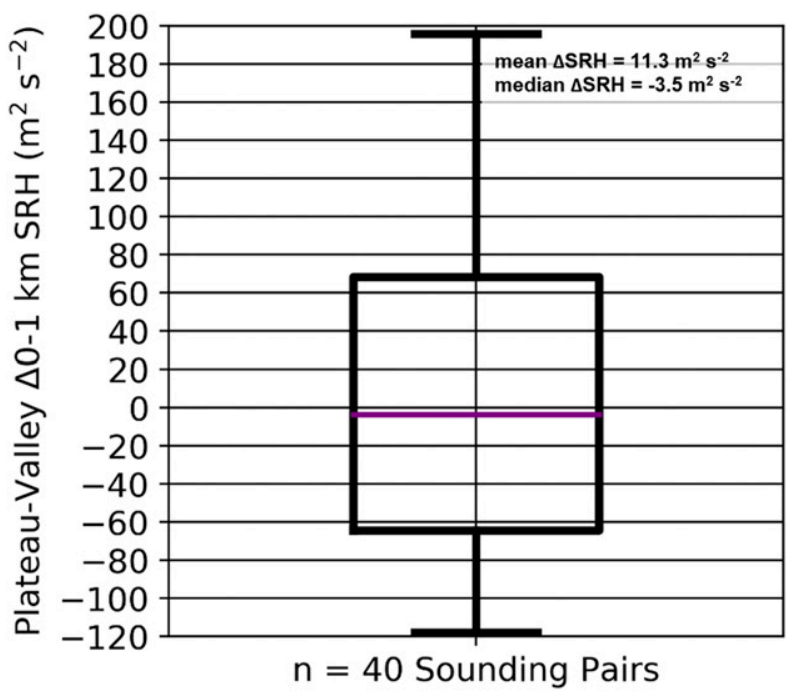

FIG. 9. Box-and-whisker plot of $0-1 \mathrm{~km}$ SRH change between NACC/Powell (Sand Mountain) and Hollywood/Scottsboro (Tennessee Valley) sounding sites for 40 pairs of observed soundings. Values greater than zero indicate higher SRH atop Sand Mountain. The box indicates the range between the 25 th and 75 th percentile of observations (the interquartile range or IQR), and the whiskers indicate values either the range from the minimum to maximum values or $1.5 \times$ IQR.

from Anniston RAP soundings (see Fig. 2 for location) described in section $2 \mathrm{c}$ were utilized. The first discrimination made in upstream $\mathrm{Fr}_{H}$ values was between cases where $\mathrm{Fr}_{H}$ on the Anniston RAP sounding was real and those where it was imaginary. Imaginary values of $\mathrm{Fr}_{H}$ are the result of cases where the stability over the lowest $250 \mathrm{~m}$ of the RAP sounding was either dry neutral or absolutely unstable (i.e., $N$ was zero or imaginary). Of the 40 sounding pairs, 18 matched with Anniston RAP soundings that featured imaginary values of $\mathrm{Fr}_{H}$. A comparison between those 18 cases and the 22 remaining cases where $\mathrm{Fr}_{H}$ was real shows a tendency for cases of real $\mathrm{Fr}_{H}$ to feature greater plateau-valley SRH changes than cases of imaginary $\mathrm{Fr}_{H}$, with imaginary cases typically featuring higher SRH in the Tennessee Valley (Fig. 15). However, both imaginary and real $\mathrm{Fr}_{H}$ datasets feature a substantial amount of variability, with a large overlap noted between the boxes.

A closer examination of the observations featuring real $\mathrm{Fr}_{H}$ upstream values indicates that a further relationship exists between $\mathrm{Fr}_{H}$ and the change in SRH between the plateau and the valley. When outlier values of extremely high $\mathrm{Fr}_{H}$ are excluded (as defined by a boxplot of real $\mathrm{Fr}_{H}$-not shown), a moderately correlated, statistically significant relationship between $\mathrm{Fr}_{H}$ and the plateau-valley SRH change is established (Fig. 16). Among elements of $\mathrm{Fr}_{H}, N$ shows the stronger correlation with $\mathrm{Fr}_{H}$

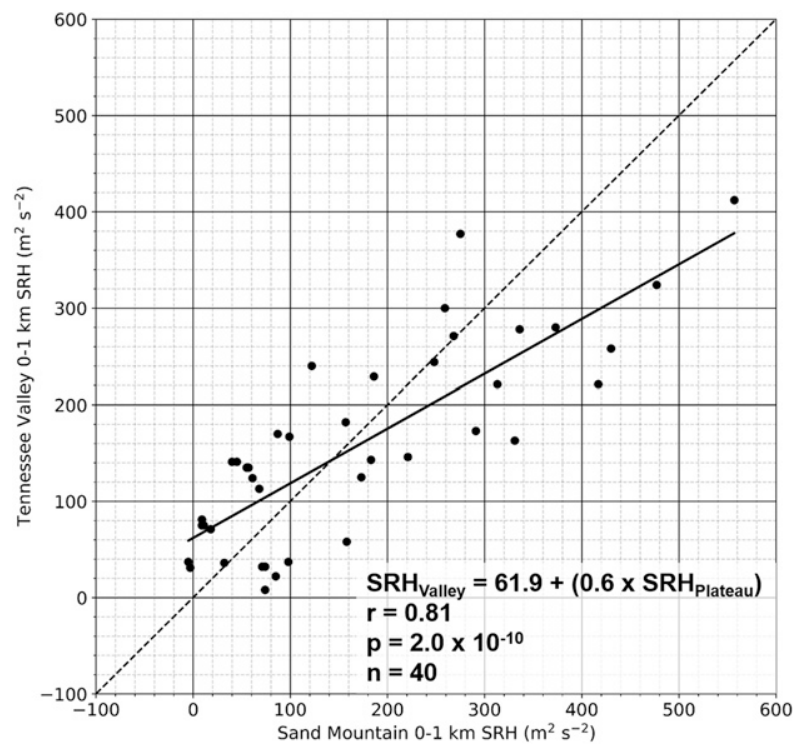

FIG. 10. Scatterplot, linear regression, and correlation analysis comparing 0-1 km SRH values atop Sand Mountain to those in the Tennessee Valley for the 40 observed sounding pairs between NACC/Powell and Hollywood/Scottsboro.

(negatively signed), while $U$ shows a weaker correlation. The cause of $N$ being more strongly correlated to SRH change than $U$ is unknown. Although the $p$ value of the linear regressions between $N, U$, and $\mathrm{Fr}_{H}$ versus SRH change indicate statistical significance, the ability to confidently diagnose a relationship between $\mathrm{Fr}_{H}$ and SRH change is limited by the small sample size of 19 . When the three excluded outlier cases are added back into the analysis, the regression slope becomes smaller

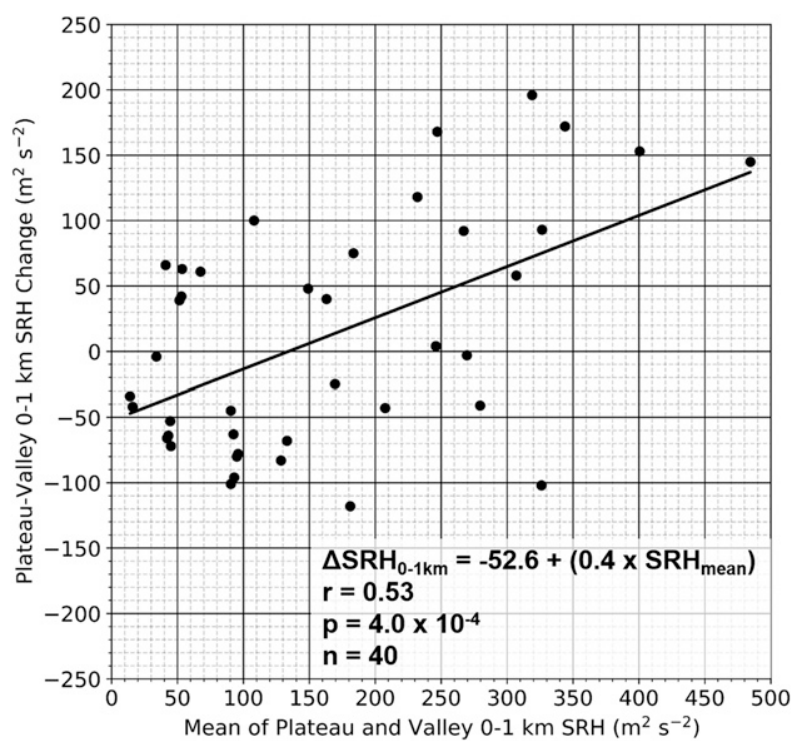

FIG. 11. As in Fig. 10, but for $0-1 \mathrm{~km}$ SRH change between plateau and valley sites and $0-1 \mathrm{~km}$ SRH mean values between sites. 


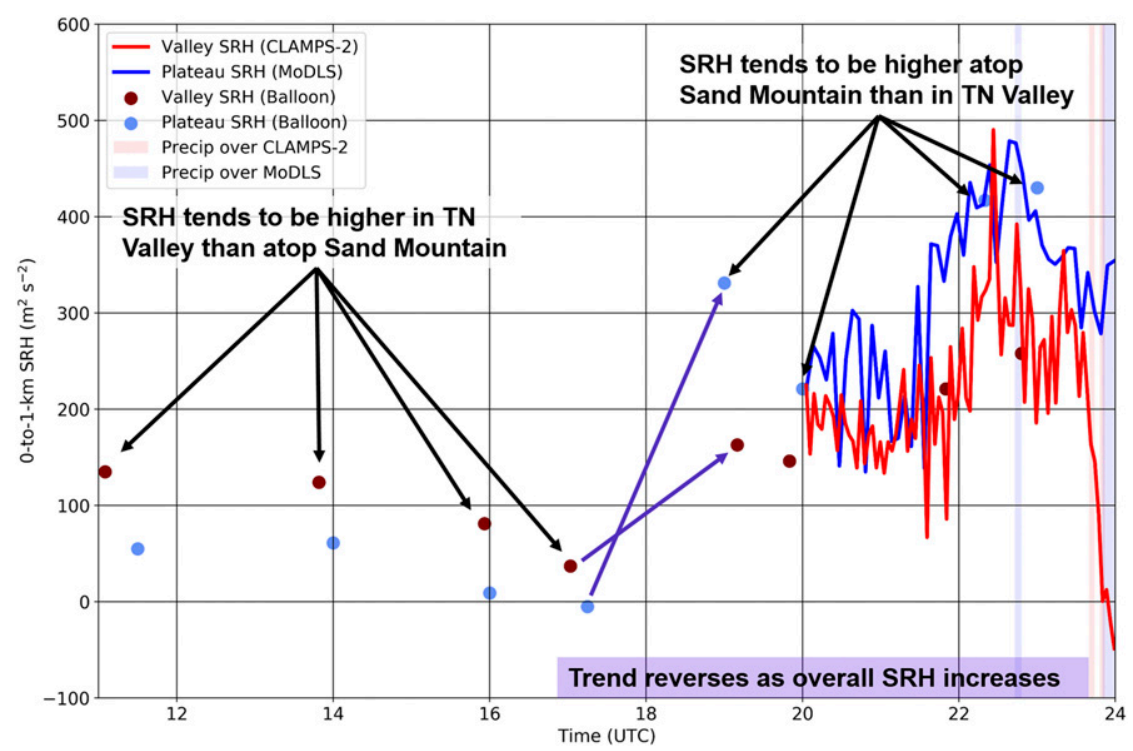

FIG. 12. Comparison of $0-1 \mathrm{~km}$ SRH values derived from MoDLS (atop Sand Mountain at NACC-red line) and CLAMPS-2 (in the Tennessee Valley at Scottsboro-blue line) to soundings (dots) between 1100 and 2359 UTC 5 Apr 2017. The 0-1 km SRH from the Doppler wind lidars is only provided after 2000 UTC, when the profilers were able to produce wind profiles at least $1 \mathrm{~km}$ deep.

and the correlation between $\mathrm{Fr}_{H}$ and $\mathrm{SRH}$ change becomes weaker (not shown), indicating that the relationship between $\mathrm{Fr}_{H}$ and SRH change may only apply to a certain range of $\mathrm{Fr}_{H}$ values and not to cases of very high values of $\mathrm{Fr}_{H}$.

With lower values of $N$ indicating less static stability and higher values of $U$ indicating stronger and/or more backed low-level flow (given the orientation of the plateaus), the relationship between $\mathrm{Fr}_{H}$ and SRH change between the plateau and the valley raises the question as to whether or not the SRH change can also be more generally linked to the tornadic favorability of the surrounding environment. To assess this question, the Anniston RAP soundings used to compare $\mathrm{Fr}_{H}$ to SRH change were used to compare effective inflow layer significant tornado parameter (STP; Thompson et al. 2012) to the SRH difference between the Powell/NACC locations atop Sand Mountain and the Hollywood/Scottsboro locations in the Tennessee Valley (Fig. 17). As with $\mathrm{Fr}_{H}$, STP is moderately, positively correlated to higher SRH atop Sand Mountain than in the Tennessee Valley for the 19 available cases where $\mathrm{Fr}_{H}$ is real and not a statistical outlier. While the relationship between STP and SRH difference may appear to be driven largely by the four data points with the highest STP values in Fig. 17, linear regression after removal of these four points yielded only minor changes in the slope and intercept of the best-fit line, but with much poorer correlation (not shown).
Given the relationships between SRH difference and STP, and SRH difference and $\mathrm{Fr}_{H}$, a larger dataset was examined using Anniston RAP soundings to compare $\mathrm{Fr}_{H}$ and STP. The upstream Anniston RAP soundings that were used in LK18 and 32 additional null cases (zero-hour forecast soundings at the approximate hour of arrival of organized nontornadic convection to the northwestern edge of Sand Mountain) were added to the

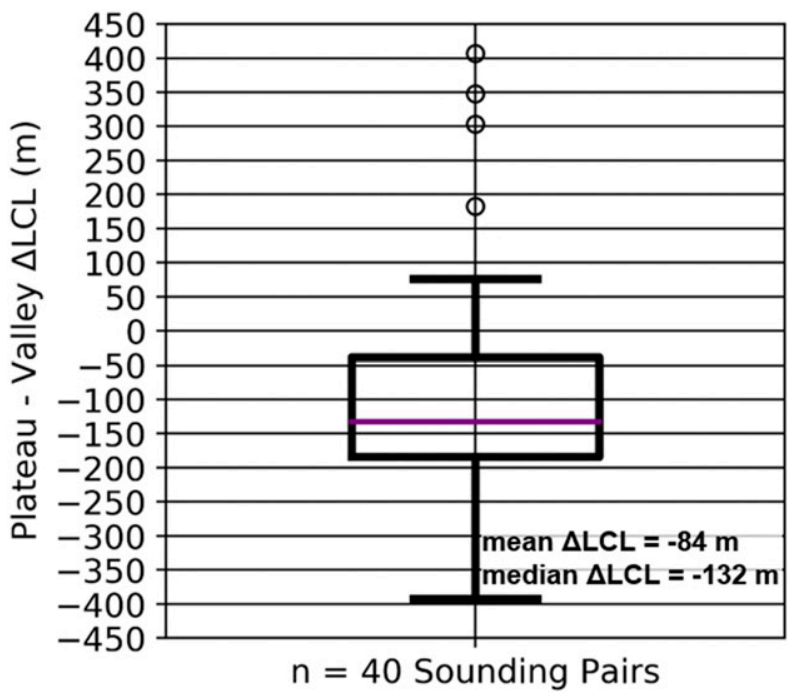

FIG. 13. As in Fig. 9, but for mixed layer LCL height change. Values greater than zero indicate higher LCLs atop Sand Mountain, and markers indicate outliers outside $1.5 \times \mathrm{IQR}$. 


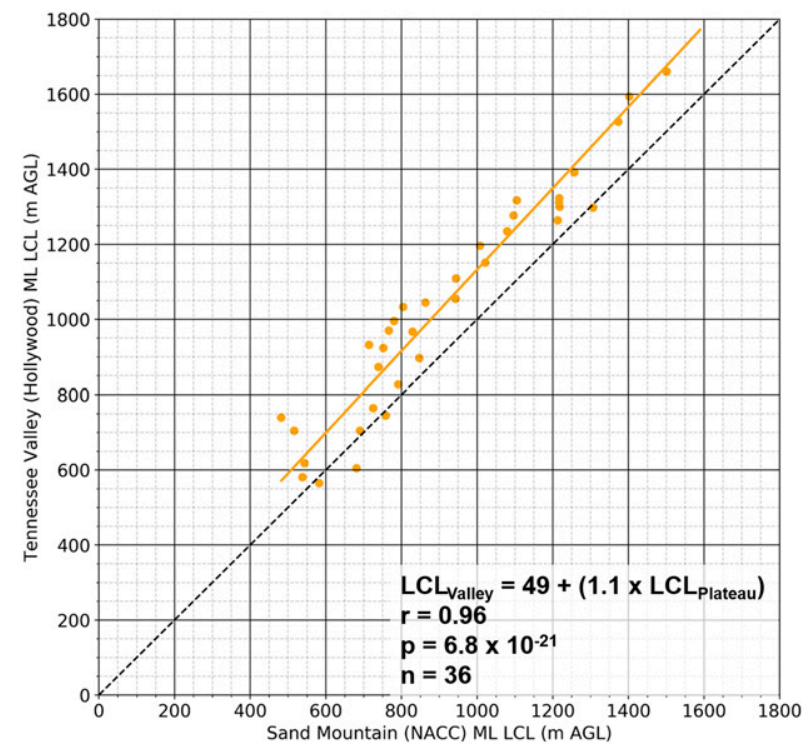

FIG. 14. As in Fig. 10, but for ML LCL, excluding the outlier values depicted in Fig. 13.

upstream soundings used for the $\mathrm{Fr}_{H}$ and STP versus observed SRH difference comparisons to create a database of 106 RAP soundings from which to compare $\mathrm{Fr}_{H}$ and STP. Of these 108 soundings, 82 contained real values of $\mathrm{Fr}_{H}, 74$ of which were not statistical outliers. These 74 soundings indicate yet another moderately correlated, statistically significant relationship between $\mathrm{Fr}_{H}$ and effective inflow layer STP from Anniston RAP soundings (Fig. 18). Similarly to the correlation between $\mathrm{Fr}_{H}$ and SRH change discussed previously in this section, the correlation between $\mathrm{Fr}_{H}$ and SRH decreases dramatically for cases of very high (outlier) $\mathrm{Fr}_{H}$ (not shown), with all eight points where $\mathrm{Fr}_{H}$ is an outlier in the dataset associated with soundings of STP $<1$.

In addition to low-level wind shear changes, the observations gathered from Sand Mountain and the Tennessee Valley indicate a strong connection between the higher elevation of Sand Mountain and lower mixedlayer LCL heights, as discussed in section 3b. While the NACC/Powell and Hollywood/Scottsboro sounding locations featured a land elevation difference of about $200 \mathrm{~m}$, the median ML LCL height difference was only about $132 \mathrm{~m}$ AGL. This discrepancy may be because most of the soundings gathered in the dataset were taken during daylight hours, when surface heating atop the plateau would increase the temperature above what it would otherwise be if the plateau surface temperature scaled adiabatically (assuming the same potential temperature) to the valley surface temperature. Additional nocturnal observations could potentially shed more light on the diurnal variation in LCL height change from valley to plateau.

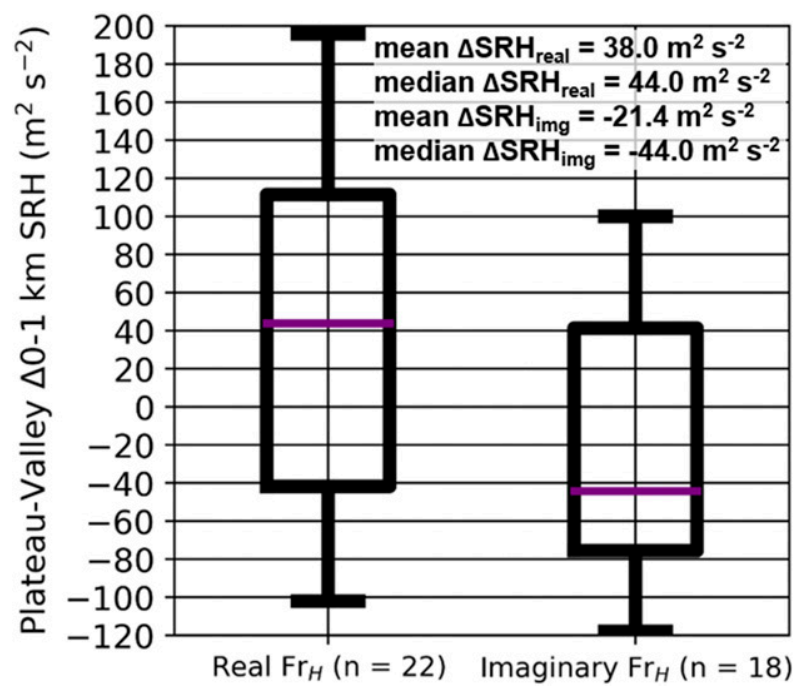

FIG. 15. As in Fig. 9, but discriminating by cases where the upstream $\mathrm{Fr}_{H}$ number at Anniston from the RAP was (left) real and (right) imaginary.

\section{Conclusions}

Observations from the VORTEX-SE 2017 field campaign and other deployments across northeastern Alabama indicate that low-level wind and thermodynamic profiles can vary substantially across underlying variations in topography, particularly between the Sand and Lookout Mountain Plateaus as compared to the adjacent Tennessee Valley. LCL heights are consistently observed to be closer to the ground surface atop Sand Mountain than in the adjacent Tennessee Valley. A downslope wind enhancement was documented herein along the northwestern edge of Sand Mountain, and given the dimensions of the plateau system, is likely fairly ubiquitous in environments where $N$ is real and $U$ is positive. Values of $0-1 \mathrm{~km} \mathrm{SRH}$ can be substantially higher in this region than either across the river in the valley or even atop the plateau. Finally, $0-1 \mathrm{~km}$ $\mathrm{SRH}$ is often greater atop Sand Mountain than in the valley (away from the base of the plateau) in cases where the upstream value of $\mathrm{Fr}_{H}$ exceeds unity and when the overall surrounding environment is favorable for tornadoes.

As discussed in section 1, the analysis presented in this paper began with two primary hypotheses: 1) low-level flow enhancement over the plateaus in tornadic environments may lead to increased SRH atop the plateaus and 2) LCL heights are lower atop the plateaus than across adjacent lower elevations, particularly in the Tennessee Valley. The results of this analysis show a strong tendency for LCL heights to be lower atop Sand Mountain than in the Tennessee Valley, with changes in LCL height appearing to be tied closely to the change in 

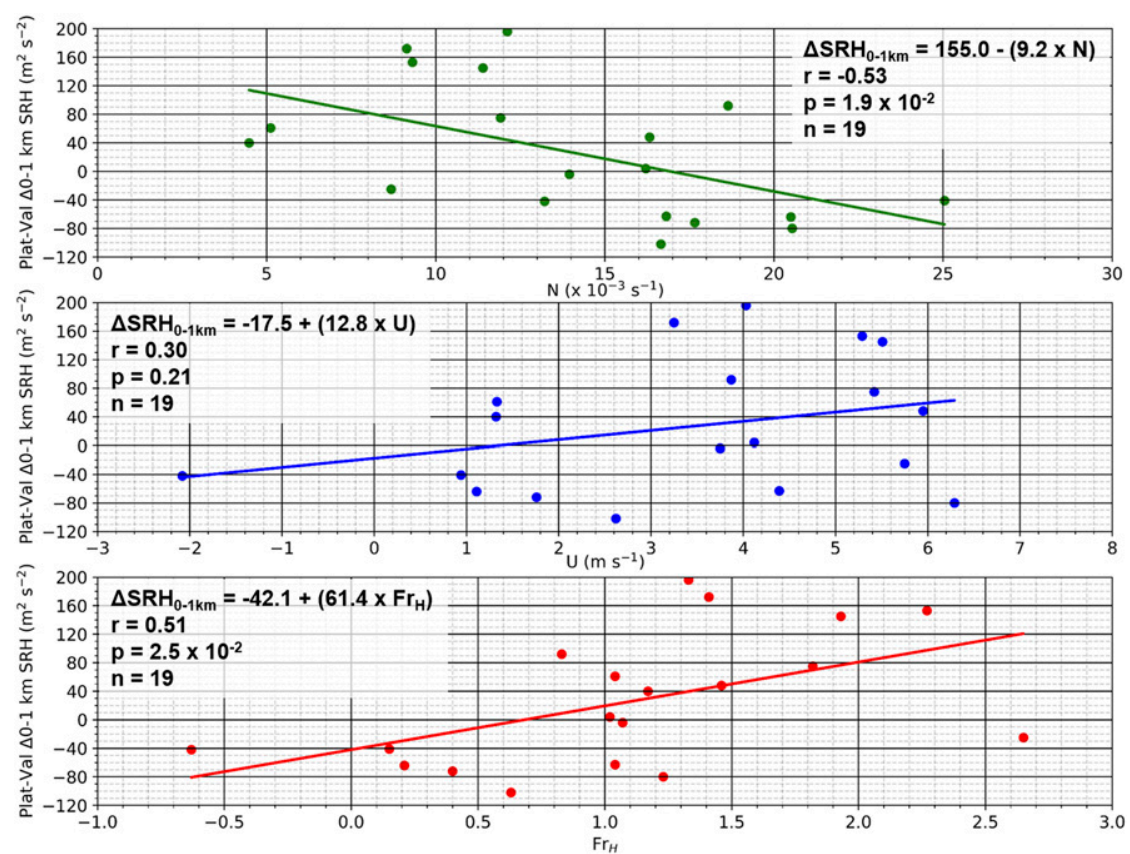

FIG. 16. Scatterplots, linear regressions, and correlations of RAP-derived (top) $N$, (middle) $U$, and (bottom) $\mathrm{Fr}_{H}$ values compared to observed $0-1 \mathrm{~km}$ SRH change from paired soundings for cases where $\mathrm{Fr}_{H}$ was real and not an outlier (outside $1.5 \times \mathrm{IQR}$ ). Values greater than zero indicate higher SRH atop Sand Mountain.

land elevation. The observations of lower LCL heights atop Sand Mountain would be consistent with past observations of the relationship between lower LCLs, more buoyant RFDs, and an increase in potential for tornadogenesis. How SRH varies between the surface of the plateaus and the adjacent Tennessee Valley is less clear. The limited observations available for this analysis suggest that SRH does tend to be higher atop the plateaus than in the valley in environments that are already favorable for tornadoes, thus increasing overall favorability for tornadogenesis atop the plateaus when the larger-scale environment is already generally supportive of tornadoes.

These results indicate that a simplified, overarching hypothesis can be developed for how the plateaus of northeastern Alabama may impact tornadogenesis patterns in northeastern Alabama:

As the overall meso- $\beta$-scale environment surrounding the plateaus of northeastern Alabama becomes more favorable for tornadogenesis, the environment atop the plateaus becomes even more favorable than surrounding locations.

This increased magnitude of favorability is driven by 1) the overall consistent tendency for lower LCL heights atop the plateaus and 2) the tendency for the plateau-valley SRH difference to increase with increasing overall environmental favorability for tornadoes.
The relationship between SRH change and environmental favorability is likely linked through the relationship between $\mathrm{Fr}_{H}$ and low-level stability and wind shear. Doppler wind lidar and balloon comparisons from the VORTEX-SE deployment on 5 April 2017 show that as the low-level flow increased through the day, the difference in low-level flow magnitude between Sand Mountain and the Tennessee Valley increased, with

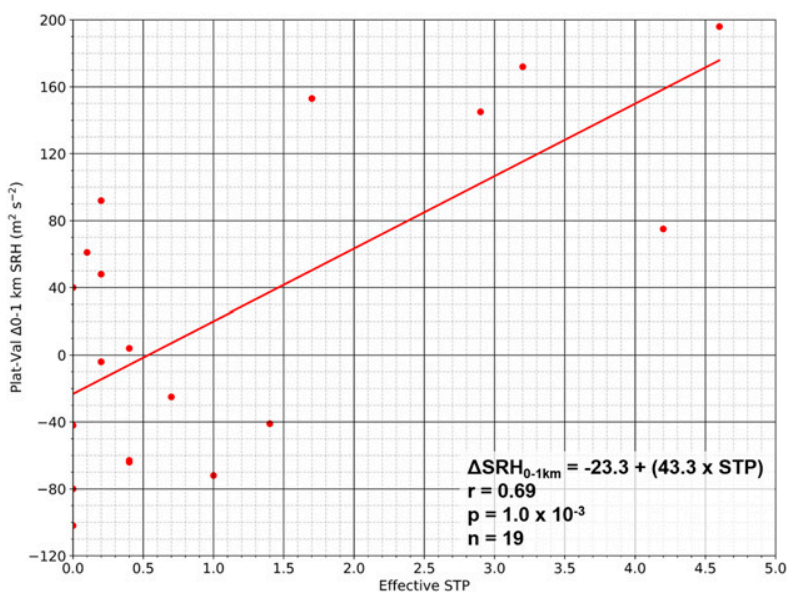

FIG. 17. As in Fig. 16, but for observed $0-1 \mathrm{~km}$ SRH change and RAP-derived effective STP values from Anniston for cases where $\mathrm{Fr}_{H}$ was real. 


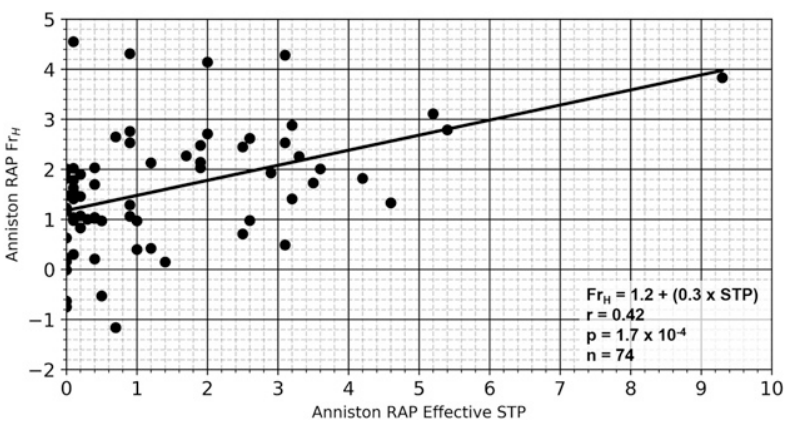

FIG. 18. Scatterplot, linear regression, and correlation for RAPderived values of $\mathrm{Fr}_{H}$ and effective STP for RAP soundings at Anniston prior to paired observational soundings, SCS tornado events, and null cases. Cases where $\mathrm{Fr}_{H}$ is an outlier on a box-andwhisker plot are excluded.

stronger low-level flow atop Sand Mountain. This increase in low-level flow over the plateau also corresponds to an increase in $0-1 \mathrm{~km}$ SRH relative to the Tennessee Valley.

The relationship between $\mathrm{Fr}_{H}$, SRH difference, and environmental favorability for tornadoes described in this work applies to two specific scenarios: 1) when $\mathrm{Fr}_{H}$ is real and 2) when $\mathrm{Fr}_{H}$ is not very large (approximately $<5$ ). In imaginary $\mathrm{Fr}_{H}$ cases, $0-1 \mathrm{~km} \mathrm{SRH}$ is typically observed to be higher in the Tennessee Valley than atop Sand Mountain. While imaginary $\mathrm{Fr}_{H}$ environments are associated with absolutely statically unstable surface- $250 \mathrm{~m}$ layers, it should be noted that of the 33 Anniston RAP/RUC soundings utilized to assess $\mathrm{Fr}_{H}$ and $\mathrm{Fr}_{L}$ values in LK18 at the hour of SCS tornadogenesis events, only six $(18 \%)$ featured imaginary $\mathrm{Fr}_{H}$ and $\mathrm{Fr}_{L}$ values when computed for a 250-m-deep layer. While this may seem initially counterintuitive, these upstream soundings suggest that weakly statically stable lower boundary layers are likely the most common stability criteria for SCS tornado events, further supporting the robustness of the results presented herein. When $\mathrm{Fr}_{H}$ is very large, the relationship between and environmental favorability for tornadoes (as assessed through STP) breaks down. Very high $\mathrm{Fr}_{H}$ cases often exhibit pathologies to tornadic favorability, most often either through weak convective instability or poor low-level water vapor content.

It bears emphasizing that the relationship between increased environmental favorability for tornadogenesis atop the northeastern Alabama plateaus and the characteristics of the surrounding environment remains a hypothesis. The observational datasets presented in this manuscript comprise small sample sizes of data (yet immensely larger than in any previous observational study of the role of terrain on severe storms). To verify the results presented in this paper and to achieve a more complete understanding of how the near-storm environment in northeast Alabama may be tied to the underlying topography, numerous additional observations must be gathered and numerical simulations of tornadic environments must be undertaken. Numerical simulation experiments looking at tornadic environments across northeastern Alabama are currently in their nascent stages and will be the focus of future work. It is also important to clarify that the results presented in this paper only relate to the near-storm environment and not directly to storm evolution. Future work must also serve to bridge the gap between observed environmental changes in northeastern Alabama and how those changes may or may not directly impact storm evolution, including whether or not these environmental changes may be linked to the observed increase in tornadogenesis reports atop the plateaus that exists in the statistical dataset presented in Fig. 1 and discussed in LK18.

Acknowledgments. The authors thank Dr. Dave Turner (NOAA ESRL Global Systems Division) for providing the CLAMPS-2 data used in this study and Drs. Temple Lee, Michael Buban, and Tilden Meyers (NOAA ARL Air Turbulence Diffusion Division) for supplying their sounding data from the VORTEX-SE 2017 field campaign. Comments from three anonymous reviewers substantially improved the final version of this manuscript. This work was completed as part of a doctor of philosophy dissertation by the lead author. Funding for this research was provided by NOAA Grants NA16OAR4590216, NA16OAR4590211, NA16OAR4590210, and NOAA Subcontract 191001.363513.04D from the Northern Gulf Institute (through Mississippi State University).

\section{REFERENCES}

Asefi-Najafabady, S., K. Knupp, J. R. Mecikalski, R. M. Welch, and D. Phillips, 2010: Ground-based measurements and dualDoppler analysis of 3-D wind fields and atmospheric circulations induced by a meso- $\gamma$-scale inland lake. J. Geophys. Res., 115, D23117, https://doi.org/10.1029/2010JD014022.

Ashley, W. S., 2007: Spatial and temporal analysis of tornado fatalities in the United States: 1880-2005. Wea. Forecasting, 22, 1214-1228, https://doi.org/10.1175/2007WAF2007004.1.

_ , and S. M. Strader, 2016: Recipe for disaster: How the dynamic ingredients of risk and exposure are changing the tornado disaster landscape. Bull. Amer. Meteor. Soc., 97, 767-786, https:// doi.org/10.1175/BAMS-D-15-00150.1.

_ A. J. Krmenec, and R. Schwantes, 2008: Vulnerability due to nocturnal tornadoes. Wea. Forecasting, 23, 795-807, https:// doi.org/10.1175/2008WAF2222132.1.

Benjamin, S. G., and Coauthors, 2016: A North American hourly assimilation and model forecast cycle: The Rapid Refresh. Mon. Wea. Rev., 144, 1669-1694, https://doi.org/10.1175/ MWR-D-15-0242.1. 
Blumberg, W. G., K. T. Halbert, T. A. Supinie, P. T. Marsh, R. L. Thompson, and J. A. Hart, 2017: SHARPpy: An open-source sounding analysis toolkit for the atmospheric sciences. Bull. Amer. Meteor. Soc., 98, 1625-1636, https://doi.org/10.1175/BAMS-D-15-00309.1.

Coleman, T. A., and P. G. Dixon, 2014: An objective analysis of tornado risk in the United States. Wea. Forecasting, 29, 366376, https://doi.org/10.1175/WAF-D-13-00057.1.

Davies-Jones, R., 1984: Streamwise vorticity: The origin of updraft rotation in supercell storms. J. Atmos. Sci., 41, 2991-3006, https:// doi.org/10.1175/1520-0469(1984)041<2991:SVTOOU>2.0.CO;2.

HALO Photonics, 2019: Stream Line-Cloud and boundary layer research LiDAR. HALO Photonics, accessed 9 June 2019, http://halo-photonics.com/Halo\%20Photonics \%20Stream \% 20Line \%20LiDAR\%20system.htm.

Hunt, J. C. R., K. J. Richards, and P. W. M. Brighton, 1988: Stably stratified shear flow over low hills. Quart. J. Roy. Meteor. Soc., 114, 859-886, https://doi.org/10.1002/qj.49711448203.

InterMet, 2019a: iMet-1-ABxn radisonde: $403 \mathrm{MHz}$ GPS with pressure sensor. Intermet Systems, 1 p., http://www.intermetsystems.com/ee/ pdf/202060_iMet-1-ABxn_Data_161006.pdf.

_- 2019b: iMet-4 radiosonde: $403 \mathrm{MHz}$ GPS synoptic technical data sheet. Intermet Systems, 2 pp., http://www.intermetsystems.com/ ee/pdf/202084-10_iMet-4_Technical_Data_Sheet.pdf.

Kis, A. K., and J. M. Straka, 2010: Nocturnal tornado climatology. Wea. Forecasting, 25, 545-561, https://doi.org/ 10.1175/2009WAF2222294.1.

Klemp, J. B., and D. K. Lilly, 1975: The dynamics of wave-induced downslope winds. J. Atmos. Sci., 32, 320-339, https://doi.org/ 10.1175/1520-0469(1975)032<0320:TDOWID >2.0.CO;2.

Krocak, M. J., and H. E. Brooks, 2018: Climatological estimates of hourly tornado probability for the United States. Wea. Forecasting, 33, 59-69, https://doi.org/10.1175/WAF-D-17-0123.1.

Lyza, A. W., and K. R. Knupp, 2017: Radar observations of a small tornado on 5 April 2017 during VORTEX-SE. 38th Conf. on Radar Meteorology, Chicago, IL, Amer. Meteor.
Soc., 159, https://ams.confex.com/ams/38RADAR/webprogram/ Paper321186.html.

- , and - 2018: A background investigation of tornado activity across the southern Cumberland Plateau terrain system of northeastern Alabama. Mon. Wea. Rev., 146, 4261-4278, https://doi.org/10.1175/MWR-D-18-0300.1.

Markowski, P. M., J. M. Straka, and E. N. Rasmussen, 2002: Direct surface thermodynamic observations within the rearflank downdrafts of nontornadic and tornadic supercells. Mon. Wea. Rev., 130, 1692-1721, https://doi.org/10.1175/ 1520-0493(2002)130<1692:DSTOWT >2.0.CO;2.

NCEI, 2019: Storm Data. Vol. 60, No. 11, 196 pp., https:// www.ncdc.noaa.gov/IPS/sd/sd.html.

NSSL, 2019: VORTEX Southeast. NSSL, accessed 9 June 2019, https://www.nssl.noaa.gov/projects/vortexse/.

Rasmussen, E. N., and D. O. Blanchard, 1998: A baseline climatology of sounding-derived supercell and tornado forecast parameters. Wea. Forecasting, 13, 1148-1164, https://doi.org/ 10.1175/1520-0434(1998)013<1148:ABCOSD>2.0.CO;2.

Strader, S. M., and W. S. Ashley, 2018: Finescale assessment of mobile home tornado vulnerability in the central and southeast United States. Wea. Climate Soc., 10, 797-812, https:// doi.org/10.1175/WCAS-D-18-0060.1.

Stull, R. B., 1988: An Introduction to Boundary Layer Meteorology. Kluwer Academic, 666 pp.

Thompson, R. L., B. T. Smith, J. S. Grams, A. R. Dean, and C. Broyles, 2012: Convective modes for significant severe thunderstorms in the contiguous United States. Part II: Supercell and QLCS tornado environments. Wea. Forecasting, 27, 1136-1154, https://doi.org/10.1175/WAF-D-11-00116.1.

Vosper, S. B., S. D. Mobbs, and B. A. Gardiner, 2002: Measurements of the near-surface flow over a hill. Quart. J. Roy. Meteor. Soc., 128, 2257-2280, https://doi.org/10.1256/qj.01.11.

Windsond, 2019: Windsond product catalogue. 9 pp., http:// windsond.com/windsond_catalog_Dec2016.pdf. 